\title{
Reductive Precipitation of Sulfate and Soluble Fe(III) By Desulfovibrio vulgaris: Electron Donor Regulates Intracellular Electron Flow and nano-FeS Crystallization
}

Chen Zhou ${ }^{1 *}$, Yun Zhou ${ }^{1,2}$, and Bruce E. Rittmann ${ }^{1}$ 


\section{ABSTRACT}

15 Fully understanding the metabolism of SRB provides fundamental guidelines for allowing

16 the microorganisms to provide more beneficial services in water treatment and resource recovery.

17 The electron-transfer pathway of sulfate respiration by Desulfovibrio vulgaris is well studied, but

18 still partly unresolved. Here we provide deeper insight by comprehensively monitoring

19 metabolite changes during $D$. vulgaris metabolism with two electron donors, lactate and pyruvate,

20 in presence or absence of citrate-chelated soluble $\mathrm{Fe}^{\mathrm{III}}$ as a competing electron acceptor. $\mathrm{H}_{2}$ was

21 produced from lactate oxidation to pyruvate, but pyruvate oxidation produced mostly formate.

22 Accumulation of lactate-originated $\mathrm{H}_{2}$ during lag phases inhibited pyruvate transformation to

23 acetate. Sulfate reduction was initiated by lactate-originated $\mathrm{H}_{2}$, but MQ-mediated $e^{-}$flow

24 initiated sulfate reduction without delay when pyruvate was the donor. When $\mathrm{H}_{2}$-induced

25 electron flow gave priority to $\mathrm{Fe}^{\mathrm{III}}$ reduction over sulfate reduction, the long lag phase before

26 sulfate reduction shortened the time for iron-sulfide crystallite growth and led to smaller

27 mackinawite $\left(\mathrm{Fe}_{1+x} \mathrm{~S}\right)$ nanocrystallites. Synthesizing all the results, we propose that electron

28 flow from lactate or pyruvate towards $\mathrm{SO}_{4}{ }^{2-}$ reduction to $\mathrm{H}_{2} \mathrm{~S}$ are through at least three routes

29 that are regulated by the $e^{-}$donor (lactate or pyruvate) and the presence or absence of another $e^{-}$

30 acceptor $\left(\mathrm{Fe}^{\mathrm{III}}\right.$ here). These routes are not competing, but complementary: e.g., $\mathrm{H}_{2}$ or formate

31 production and oxidation were necessary for sulfite and disulfide/trisulfide reduction to sulfide.

32 Our study suggests that the $e^{-}$donor provides a practical tool to regulate and optimize SRB-

33 predominant bioremediation systems.

35 Key Words: D. vulgaris; $\mathrm{SO}_{4}{ }^{2-}$ reduction; Soluble $\mathrm{Fe}^{\mathrm{III}}$ reduction; Iron-sulfide; Crystallization 


\section{Introduction}

37 In nature, sulfate $\left(\mathrm{SO}_{4}{ }^{2-}\right)$ reduction by sulfate-reducing bacteria (SRB) significantly

38 influences the biogeochemistry of anaerobic environments and plays a crucial role in global

39 sulfur cycling (Fredrickson and Gorby 1996, Fredrickson et al. 2000, Sani et al. 2004, Zachara et

40 al. 2001). In practice, their capacity for concomitant $\mathrm{SO}_{4}{ }^{2-}$ and $\mathrm{Fe}^{\mathrm{III}}$ reduction has been widely

41 exploited to remediate acid mine drainage (AMD) (Bai et al. 2013, Sánchez-Andrea et al. 2014),

42 and the consequent iron-sulfide production is attracting greater attention for its potential

43 application in long-term uranium remediation (Abdelouas et al. 1999, Bi et al. 2013, Moyes et al.

44 2000) - for example, nanocrystalline iron-sulfide (nano-FeS) can be applied to effectively retard

45 oxidative dissolution of immobilized U(IV) (Bi and Hayes 2014) or accelerate microbial

46 dechlorination of chlorinated organics (Huo et al. 2016). On the other hand, $\mathrm{SO}_{4}{ }^{2-}$ reduction

47 needs to be minimized to avoid generation of hydrogen sulfide that is corrosive, toxic, and

48 inhibitory to other desired processes such as denitrification (Zhao et al. 2013a, Zhao et al. 2013b,

49 Zhao et al. 2014). Thus, fully understanding the metabolism of SRB provides fundamental

50 guidelines for allowing the microorganisms to provide more beneficial services in water

51 treatment and resource recovery.

52 Numerous studies of the electron-transfer pathway in respiratory sulfate reduction have

53 focused on Desulfovibrio spp., a group of mesophilic SRB belonging to the Gram-negative

54 Deltaproteobacteria class. Nevertheless, electron transfer in sulfate reduction remains 55 incompletely understood and even controversial.

56 Earlier models (Elias et al. 2004, Heidelberg et al. 2004, Pankhania et al. 1988, Pieulle et al.

57 1997, Voordouw 2002) feature lactate $\left(\mathrm{CH}_{3} \mathrm{CHOHCOO}^{-}\right)$, an exogenous electron donor and 
carbon source, first being fermented to pyruvate $\left(\mathrm{CH}_{3} \mathrm{COCOO}^{-}\right)$by lactate dehydrogenase (Ldh),

59 releasing protons and electrons. These protons and electrons react with membrane-bound

60 hydrogenases (Coo Hase) to form molecular hydrogen $\left(\mathrm{H}_{2}\right)$. Pyruvate is then fermented to

61 acetate $\left(\mathrm{CH}_{3} \mathrm{COO}^{-}\right)$through soluble pyruvate:ferredoxin oxidoreductase (Por) in the cytoplasm,

62 also forming either $\mathrm{H}_{2}$ through $\mathrm{Coo} \mathrm{Hase}$, formate $\left(\mathrm{CHOO}^{-}\right)$through cytoplasmic pyruvate

63 formate lyase $(\mathrm{Pfl})$, or both. As intracellular electron carriers, $\mathrm{H}_{2}$ and $\mathrm{CHOO}^{-}$diffuse to the

64 periplasm; there, they can be oxidized back to protons and electrons by periplasmic

65 hydrogenases (hyn) and formate dehydrogenases (fdh), respectively. The electrons from

66 oxidation of $\mathrm{H}_{2}$ and $\mathrm{CHOO}^{-}$are transported to Type I cytochrome $c_{3}\left(\mathrm{TpI} c_{3}\right)$ and then transported

67 through the cytochrome network back to the cytoplasm, where $\mathrm{SO}_{4}{ }^{2-}$ is activated by the ATP

68 generated through lactate fermentation, and the consequent adenosinephosphosulfate (APS)

69 accepts the electrons and is gradually reduced to sulfide. In this so-called "hydrogen cycling

70 model (Peck et al. 1987)", lactate oxidation and $\mathrm{SO}_{4}{ }^{2-}$ reduction are independent processes that

71 can be linked only by the intracellular electron carriers. When pyruvate, $\mathrm{H}_{2}$, or formate is an

72 exogenous electron donor, it can enter into this pathway of electron transfer.

73 This original model has been challenged by recent studies (Keller and Wall 2011, Keller et

74 al. 2014, Noguera et al. 1998, Venceslau et al. 2010, Walker et al. 2009) that propose that sulfate

75 also can accept electrons directly from lactate and pyruvate oxidations mediated by menaquinone

76 (MQ) and ferredoxin redox loops, respectively; both electron flows are catalyzed by the

77 membrane-bound quinone-interacting oxidoreductases (Qmo) complex (Ramos et al. 2012). In

78 this new model, the role of $\mathrm{H}_{2}$ cycling in sulfate reduction is diminished by half (Noguera et al.

79 1998) or even to almost nothing (Rabus et al. 2006). However, the latest studies (Keller and

80 Wall 2011, Oliveira et al. 2008, Santos et al. 2015) propose that DsrMKJOP, a membrane-bound 
81 dissimilatory sulfite reductase complex, catalyzing the last step of sulfate reduction

82 (disulfide/trisulfide to free sulfide), may carry electrons exclusively from $\mathrm{TpI} c_{3}$; in this scenario,

83 electron transfer indirectly through $\mathrm{H}_{2}$ cycling and directly through $\mathrm{MQ}$ mediation are

84 complementary pathways instead of alternative pathways. Furthermore, some of these new

85 models (Keller and Wall 2011, Pereira et al. 2011) propose that, during sulfate-reduction, $\mathrm{H}_{2}$

86 production is attributed only to pyruvate oxidation to acetate, while electrons from lactate

87 oxidation to pyruvate are exclusively involved in the MQ redox loops.

88 In this study, we provide deeper insight into some of the controversial steps of electron

89 transfer by D. vulgaris, including 1) whether sulfate reduction can directly utilize electrons from

90 lactate oxidation to pyruvate; 2 ) whether lactate oxidation to pyruvate exclusively produces $\mathrm{H}_{2}$ in

91 absence of $\mathrm{SO}_{4}{ }^{2-}$ reduction; 3) whether pyruvate oxidation to acetate generates electron carriers

92 for indirect/transmembrane $\mathrm{SO}_{4}{ }^{2-}$ reduction; and, if so, 4) whether pyruvate oxidation to acetate

93 produces formate alone. In order to differentiate combined disulfide/trisulfide from free sulfide,

94 we introduced soluble iron, which combines only with free sulfide to form iron-sulfide

95 precipitates. In addition, $\mathrm{Fe}^{\mathrm{III}}$ is able to be reduced in the periplasm by $\mathrm{TpI} c_{3}$, which can carry

96 electrons from $\mathrm{H}_{2}$ or formate (Elias et al. 2004); thus, it can be used to retard indirect sulfate

97 reduction featuring membrane-crossing electron transfer. Consistent with previous studies (Zhou

98 et al. 2015a, Zhou et al. 2014a), amorphous iron sulfide formed initially by D. vulgaris was

99 crystallized into mackinawite nanoparticles, but to different degrees depending on the electron

100 donor. In our study, differences in electron flows provide new interpretations about the

101 underlying mechanisms of iron-sulfide crystallization indirectly affected by D. vulgaris. 


\section{Material and Methods}

103 Strain, growth medium, and culturing conditions

104 D. vulgaris was purchased from American Type Culture Collection (ATCC \#29579) and

105 grown in 160-ml serum bottles with $100 \mathrm{ml}$ sterile standard ATCC 1249 medium and a

106 headspace of $\mathrm{N}_{2}$. The serum bottles were sealed with rubber stoppers and aluminum caps and

107 incubated in a shaker $(200 \mathrm{rpm})$ at $30^{\circ} \mathrm{C}$ right after inoculation. The cells were transferred to

108 new culturing bottles every four to seven days by injecting 2-3 ml inoculum into new culturing

109 bottles containing freshly prepared medium.

\section{Preparation of biomass suspension}

111 Right before the electron-flow tests, we prepared a fresh biomass suspension from culturing

112 bottles in which bacterial growth had reached the late log phase after a 48-hour incubation (Zhou

113 et al. (2014a). We followed the procedures of Zhou et al. (2014b) for preparing biomass

114 suspensions. In brief, we transferred the liquid part from the culturing bottles into centrifuge

115 tubes, centrifuged the tubes, discarded the supernatants, and re-suspended the remaining pellets

116 in the basic assay solution (described below). We repeated this cycle three times and then

117 distributed $5 \mathrm{~mL}$ of the biomass suspension into each test bottle. This gave 4-5 mg/L protein as

118 the initial biomass concentration in each test bottle.

\section{Experimental conditions}

120 The basic assay solution in all the electron-flow tests was modified from the standard ATCC

1211249 medium. It featured $5 \mathrm{mM}$ sulfate (as $\mathrm{Na}_{2} \mathrm{SO}_{4}$, the respiratory electron acceptor), $15 \mathrm{mM}$

122 citrate (as $\mathrm{Na}_{3} \mathrm{C}_{6} \mathrm{H}_{5} \mathrm{O}_{7}$, the primary $\mathrm{pH}$ buffer and soluble Fe stabilizer), $2 \mathrm{mM}$ phosphate (as 
$123 \mathrm{~K}_{2} \mathrm{HPO}_{4}$, the $\mathrm{P}$ source and part of $\mathrm{pH}$ buffer), $7.5 \mathrm{mM}$ calcium (as $\mathrm{CaCl}_{2}$, the calcium source), 15

$124 \mathrm{mM}$ magnesium (as $\mathrm{MgCl}_{2}$, the magnesium source), and $20 \mathrm{mM}$ ammonium (as $\mathrm{NH}_{4} \mathrm{Cl}$, the $\mathrm{N}$

125 source). In particular, yeast extract was replaced with $5 \mathrm{~mL}$ of trace metal stock solution

126 described by Chung et al. (2006) for all the electron-flow tests.

127 In the primary study, we tested four conditions based on different combinations of electron

128 donor and iron source supplemented into the basic assay solution: sodium L-lactate plus ferrous

129 chloride $\left(\mathrm{Lac}+\mathrm{Fe}^{\mathrm{II}}\right)$; sodium L-lactate plus ferric chloride $\left(\mathrm{Lac}+\mathrm{Fe}^{\mathrm{III}}\right)$; sodium pyruvate plus

130 ferrous chloride $\left(\mathrm{Pyr}+\mathrm{Fe}^{\mathrm{II}}\right)$; and sodium pyruvate plus ferric chloride $\left(\mathrm{Pyr}+\mathrm{Fe}^{\mathrm{III}}\right)$. We added the

131 same electron equivalent concentration of lactate $(12 \mathrm{mM})$ and pyruvate $(24 \mathrm{mM})$ before

132 autoclaving and the same mole concentration of iron sources $(5 \mathrm{mM})$ after autoclaving. The

133 ratios of electron donors to acceptors were matched so that electrons released from lactate or

134 pyruvate would be almost completely consumed for reductions of all $\mathrm{SO}_{4}{ }^{2-}$ and $\mathrm{Fe}^{\mathrm{III}}$ and for

135 biomass growth. We prepared two bottles as duplicates for each condition.

136 In a supplementary study, we tested the four conditions with the same liquid matrix and

137 incubation conditions as in the primary study, except that we continuously purged the headspaces

138 with filtered UHP $\mathrm{N}_{2}$ gas at a constant pressure of 2 psig (1.14 atm absolute pressure) throughout

139 incubation in order to remove endogenously produced $\mathrm{H}_{2}$ gas.

\section{Analytical methods}

141 In the primary study, we routinely collected 3-ml liquid samples from the bottles using

142 sterile syringes and needles. We used unfiltered samples for protein and $\mathrm{pH}$ measurement, and 143 we filtered samples through $0.22-\mu \mathrm{m}$ membrane filter for other chemical analyses. Protein, 144 sulfide, soluble Fe(III), and total soluble Fe concentrations were assayed using a UV-Visible 
145 spectrophotometer (Cary 50 Bio, Varian, Inc., Santa Clara, CA). In particular, soluble Fe species

146 were analyzed by the colorimetric 5-sulfosalicylicacid (SSA) method (Karamanev et al. 2002).

147 Concentrations of anions - including sulfate, sulfite, thiosulfate, and phosphate - were analyzed

148 using ion-exchange chromatography (IC, Dionex ICS2000; U.S. EPA, 1993). Volatile fatty acids

149 (acetate, lactate, pyruvate, and formate) were identified and quantified using high-performance

150 liquid chromatography (HPLC; Shimadzu 20AT) with a refractive index detector (RID). $\mathrm{H}_{2}$ in

151 the headspace was analyzed using a gas chromatograph (GC 2010, Shimadzu) equipped with a

152 thermal conductivity detector (TCD). Elemental sulfur was extracted in tetrachloroethylene

153 solvent and analyzed using an ultra-performance liquid chromatography (UPLC; Waters, Milford,

154 MA, USA). Further details of sample preparation procedures and instrument conditions were

155 described in previous studies (Zhou et al. 2014a, Zhou et al. 2014b).

156 In the supplementary study, we only analyzed concentrations of S and Fe species in the 157 beginning and the end of the incubation period. In addition, iron-sulfide precipitates were 158 quantified by digesting unfiltered samples in $0.5 \mathrm{M} \mathrm{HCl}$ solution for iron extraction (details 159 described in Carpenter et al. (2015) and calculating the difference of measured total soluble iron 160 before and after $\mathrm{HCl}$ treatment. The unidentified $\mathrm{S}$ species in each bottle were calculated by 161 subtracting the total concentration of all detectable $\mathrm{S}$ species $-\mathrm{SO}_{4}{ }^{2-}, \mathrm{SO}_{3}{ }^{2-}, \mathrm{S}_{2} \mathrm{O}_{3}{ }^{2-}, \mathrm{S}^{0}, \mathrm{~S}^{2-}$ 162 (including aqueous and gaseous $\mathrm{H}_{2} \mathrm{~S}$ ), and $\mathrm{FeS}$ - in the end of incubation from the measured total $163 \mathrm{SO}_{4}{ }^{2-}$ concentration in the beginning of incubation.

\section{Mathematical modeling}

165 Experimental results of substrate utilizations were fit to logistic, first-order, or Monod 166 models (as appropriate) using SigmaPlot 12.5 software (SPSS, Inc., Chicago, IL, USA). The 
167 models used for different purposes are introduced in the Results section, and details are provided

168 in Electronic Supplementary Material (ESM). Kinetic and stoichiometric parameters were

169 calculated from the experimental data using the equations described in Rittmann and McCarty

170 (Rittmann and McCarty 2001). Electron balances were determined based on reaction

171 stoichiometry modified from our previous study (Zhou et al. 2015b) and is detailed in ESM.

\section{Separation of solids from culture medium}

173 After the 90-hour incubation, we opened up all bottles in the primary study in an anaerobic

174 glove box after 15-min centrifugation at 3,000 $g$ using a benchtop centrifuge (VWR Clinic 200)

175 located inside the glove box, removed supernatant, and transferred the precipitates and residual 176 liquid $(\sim 10 \mathrm{~mL})$ into sterile $50-\mathrm{ml}$ centrifuge tubes. We repeated water addition + centrifugation

$177+$ supernatant removal three times, and then we freeze dried the solids at $-50^{\circ} \mathrm{C}$ under $10 \mathrm{~Pa}$ 178 vacuum for 2 days; under this cold and $\mathrm{O}_{2}$-free scenario, FeS oxidation was negligible. The 179 dried solids were ground and stored anaerobically in sealed bottles in the $-20^{\circ} \mathrm{C}$ freezer for 180 further analyses.

\section{Solid characterizations}

182 We examined the powders using X-ray diffractometer (XRD; Rigaku D/Max-IIB with 183 monochromated $\mathrm{Cu} K_{\alpha}$ radiation) and transmission electron microscopy (TEM; FEI Corp., 184 Eindhoven, The Netherlands). We estimated average particle sizes of the mackinawite in those 185 samples by visually measuring lattice fringe dimensions in TEM images and by mathematically 186 calculating crystallite plane thickness in XRD spectra on the basis of the Scherrer equation:

$187 t=\frac{0.9 \lambda}{B \cos \theta_{\mathrm{B}}}$ 
188 where $t$ is thickness of the particles $(\AA)$ in a direction perpendicular to the reflection $(001)$ planes, $189 \lambda$ is wavelength of the incident X-ray $(\AA), B$ is full width at half maximum (FWHM) of the $(001)$ 190 peak (radian), and $\theta_{\mathrm{B}}$ is the Bragg angle (degrees) at the (001) peak (Cullity 1978; Hyun and 191 Hayes, 2009). 


\section{Results}

Figures 1 and 2 profile the changes of substrates, metabolites, $\mathrm{pH}$, and biomass (represented 194 by protein concentration) during the 90-hour incubations of $D$. vulgaris utilizing lactate or 195 pyruvate as the sole electron donor, respectively. Table 1 summarizes kinetic parameters 196 estimated from these experimental results.

197 Conversion of $\mathrm{SO}_{4}{ }^{2-}$ and soluble $\mathrm{Fe}$ to iron-sulfide by $\mathrm{D}$. vulgaris utilizing lactate or 198 pyruvate

Within 90 hours, most $\mathrm{SO}_{4}{ }^{2-}$ was reduced for all conditions. $\mathrm{Fe}^{\mathrm{III}}$ was first converted to $\mathrm{Fe}^{\mathrm{II}}$, 200 and $\mathrm{Fe}^{\mathrm{II}}$ was depleted along with $\mathrm{SO}_{4}{ }^{2-}$ reduction, as $\mathrm{FeS}$ was formed. The measured 201 concentrations of other $\mathrm{S}$ species $-\mathrm{SO}_{3}{ }^{2-}, \mathrm{S}_{2} \mathrm{O}_{3}{ }^{2-}, \mathrm{S}^{0}$, and $\mathrm{S}^{2-}$ - were below detection limits $202\left(<0.02 \mathrm{mM}\right.$, or $<0.4 \%$ of initial $\mathrm{SO}_{4}{ }^{2-}$; data not shown) throughout the incubation period; this 203 confirms that the lost $\mathrm{SO}_{4}{ }^{2-}$ was completely reduced to sulfide and rapidly precipitated with iron.

204 The lag phase before $\mathrm{SO}_{4}{ }^{2-}$ reduction was longer during lactate utilization was lagged more 205 than during pyruvate utilization

206 Once launched, $\mathrm{SO}_{4}{ }^{2-}$ reduction was rapid for all conditions. The maximum rates were 207 moderately higher for pyruvate $(3.4-3.7 \mathrm{mM} / \mathrm{d})$ than for lactate $(3.1-3.2 \mathrm{mM} / \mathrm{d})$, as quantified by 208 the logistic decay model, which is summarized in Fig. 3A. However, the duration of lag-phases 209 and lag patterns prior to the rapid takeoff of $\mathrm{SO}_{4}{ }^{2-}$ reduction varied considerably for the different 210 conditions.

211 In Lac+Fe ${ }^{\mathrm{II}}$ bottles (A-1 in Fig. 1), the $\mathrm{SO}_{4}{ }^{2-}$ concentration did not change significantly $(<3 \%$

212 change) during the first 30 hours, but then was rapidly reduced to $<0.1 \mathrm{mM}$ in the following 40

213 hours; the approximate zero-order rate was $3.1 \mathrm{mM} / \mathrm{d}$ at around the $50^{\text {th }}$ hour. In contrast, the 
$214 \mathrm{Pyr}+\mathrm{Fe}^{\mathrm{II}}$ bottles (A-1 in Fig. 2) launched $\mathrm{SO}_{4}{ }^{2-}$ reduction along with pyruvate consumption 215 without obvious delay; the maximum rate was $3.7 \mathrm{mM} /$ day at the $30^{\text {th }}$ hour.

216 In the presence of $\mathrm{Fe}^{\mathrm{III}}$, rapid $\mathrm{SO}_{4}{ }^{2-}$ reduction occurred only after most $\mathrm{Fe}^{\mathrm{III}}$ was reduced to

$217 \mathrm{Fe}^{\mathrm{II}}$. In Lac+Fe ${ }^{\mathrm{III}}$ bottles (B-1 in Fig. 1), $\mathrm{SO}_{4}{ }^{2-}$ reduction was not detectable until $94 \%$ of $\mathrm{Fe}^{\mathrm{III}}$

218 was reduced to $\mathrm{Fe}^{\mathrm{II}}$ at the $56^{\text {th }}$ hour; $\mathrm{SO}_{4}{ }^{2-}$ reduction then was initiated with an approximate zero-

219 order rate of $3.2 \mathrm{mM} / \mathrm{d}$. In Pyr+Fe ${ }^{\mathrm{III}}$ bottles (B-1 in Fig. 2), $\mathrm{SO}_{4}{ }^{2-}$ reduction was retarded, but not

220 entirely inhibited at first: By the $56^{\text {th }}$ hour and with $88 \% \mathrm{Fe}^{\mathrm{III}}$ reduction, $0.9 \mathrm{mM}(16 \%)$ of the

221 starting $\mathrm{SO}_{4}{ }^{2-}$ was reduced, and $1.0 \mathrm{mM}$ total $\mathrm{Fe}$ was lost as a result of $\mathrm{FeS}$ precipitation.

\section{Retardation of $\mathrm{Fe}^{\mathrm{III}}$ reduction for pyruvate}

223 When lactate was the added electron donor, $\mathrm{Fe}^{\mathrm{III}}$ reduction exhibited first-order kinetics $\left(\mathrm{R}^{2}\right.$ $224=0.9992$ ) with a rate constant of $1.2 \mathrm{~d}^{-1}$ (details in Fig. $3 \mathrm{~B}$ ), as $\mathrm{SO}_{4}{ }^{2-}$ reduction was not 225 detectable (B-1 in Fig. 1). When pyruvate was the added electron donor, Fe ${ }^{\mathrm{III}}$ reduction was 226 initially retarded, along with slowed $\mathrm{SO}_{4}{ }^{2-}$ reduction (B-1 in Fig. 2). After the initial 40 hours, 227 when $57 \%$ of $\mathrm{Fe}^{\mathrm{III}}$ and $10 \%$ of $\mathrm{SO}_{4}{ }^{2-}$ had been depleted, the $\mathrm{Fe}^{\mathrm{III}}$-reduction rate reached its 228 maximum, a first-order rate of $1.9 \mathrm{~d}^{-1}$ (Fig. 3B).

\section{$229 \mathbf{H}_{2}$ and pyruvate accumulations and contribution to $\mathrm{Fe}^{\mathrm{III}}$ reduction in lactate bottles}

230 We detected transient $\mathrm{H}_{2}$ accumulation before rapid $\mathrm{SO}_{4}{ }^{2-}$ reduction in all lactate bottles, but 231 no $\mathrm{H}_{2}$ above the detection limit $(0.001 \mathrm{~atm})$ throughout the incubation in pyruvate bottles. All $\mathrm{H}_{2}$ production was derived from lactate fermentation. In each $\mathrm{Lac}+\mathrm{Fe}^{\mathrm{II}}$ bottle (A-2 in

233 Fig. 1), 0.16 mmole lactate was consumed during the first 30 hours, with minimal $\mathrm{SO}_{4}{ }^{2-}$ 234 reduction and bacterial growth (consuming $<1 \%$ electrons from lactate), and nearly equal 235 amounts (totally 0.17 mmole in a single $160-\mathrm{mL}$ serum bottle containing $100 \mathrm{~mL}$ liquid) of $\mathrm{H}_{2}$ 
236 and pyruvate were generated. For pyruvate, 53\% was detected directly, and $47 \%$ was detected

237 indirectly from its fermentation to acetate. An electron balance on the experimental data (Fig.

238 4A) suggests that $>99 \%$ of the $\mathrm{H}_{2}$ that was produced came from lactate fermentation to pyruvate;

239 in other words, the $\mathrm{H}_{2}$ produced from pyruvate transformation to acetate was negligible.

240 Contribution of $\mathrm{H}_{2}$ and pyruvate to Fe $e^{\text {III }}$ reduction. In Lac+Fe ${ }^{\mathrm{III}}$ bottles (B-2 in Fig. 1), $\mathrm{H}_{2}$

241 and pyruvate accumulated up to 0.09 and 0.14 mmole during the first 56 hours, which had no

$242 \mathrm{SO}_{4}{ }^{2-}$ reduction; this represented only $41 \%$ of the electrons released from lactate (2\% was in

243 biomass). As the electron balance (Fig. 4B) reveals, $\mathrm{H}_{2}$ was linked to $61 \%$ of the measured $\mathrm{Fe}^{\mathrm{III}}$

244 reduction, while pyruvate transformation to acetate was responsible for reducing the other $39 \%$ $245 \mathrm{Fe}^{\mathrm{III}}$.

246 Subsequent $\mathrm{H}_{2} /$ pyruvate depletion for $\mathrm{SO}_{4}{ }^{2-}$ reduction. In all lactate bottles, once rapid $247 \mathrm{SO}_{4}{ }^{2-}$ reduction was initiated, $\mathrm{H}_{2}$ and pyruvate concentrations began to decrease gradually. Most 248 electrons released from depleted $\mathrm{H}_{2}$ and pyruvate were targeted to $\mathrm{SO}_{4}{ }^{2-}$ reduction, the exclusive 249 electron-accepting process at that time. Thus, the accumulated $\mathrm{H}_{2}$ was responsible for at least $9 \%$ 250 and $5 \%$ of $\mathrm{SO}_{4}{ }^{2-}$ reduction in $\mathrm{Lac}+\mathrm{Fe}^{\mathrm{II}}$ and $\mathrm{Lac}+\mathrm{Fe}^{\mathrm{III}}$ bottles, respectively.

\section{Formate buildup and contribution to $\mathrm{Fe}^{\mathrm{III}}$ reduction}

252 We observed formate accumulation in all bottles. Electron flow calculation for lactate 253 bottles (Fig. 4) suggests that formate was the exclusive product from pyruvate transformation to 254 acetate, as $\mathrm{H}_{2}$ production through this process was negligible $(<1 \%)$. Prior to rapid $\mathrm{SO}_{4}{ }^{2-}$ 255 reduction, formate slowly accumulated along with acetate; when $\mathrm{Fe}^{\mathrm{III}}$ was present, the detected 256 formate concentrations were always lower than the total formate production, as reflected by the 257 acetate concentration according to the stoichiometry (Eqn. S2-2); this confirms that partial 
258 utilization of formate was responsible for $39 \%$ and $100 \%$ of $\mathrm{Fe}^{\mathrm{III}}$ reduction in $\mathrm{Lac}^{\mathrm{F}} \mathrm{Fe}^{\mathrm{III}}$ and $259 \mathrm{Pyr}+\mathrm{Fe} \mathrm{e}^{\mathrm{III}}$ bottles, respectively.

\section{Depriving $\mathrm{H}_{2}$ resulted in incomplete $\mathrm{SO}_{4}{ }^{2-}$ reduction}

In the supplementary study, we observed an obvious discrepancy between the metabolic

262 activities with lactate versus pyruvate, as shown in the final S speciation chart in Figure 5. On

263 the one hand, continuous $\mathrm{N}_{2}$ purging removed most biogenic $\mathrm{H}_{2}$, depriving $D$. vulgaris of at least 264 one-half of the electrons released from lactate for $\mathrm{H}_{2}$-mediated $\mathrm{SO}_{4}{ }^{2-}$ reduction (according to

265 stoichiometry). In the lactate bottles, however, $\mathrm{SO}_{4}{ }^{2-}$ depletion was still over $60 \%$, which

266 indicates that D. vulgaris partially bypassed the fermentation pathway and directly delivered 267 electrons through MQ mediation for $\mathrm{SO}_{4}{ }^{2-}$ reduction. Furthermore, D. vulgaris accomplished 268 complete $\mathrm{Fe}^{\mathrm{III}}$ and $\sim 90 \% \mathrm{SO}_{4}{ }^{2-}$ reductions with $\mathrm{H}_{2}$ stripping, which demonstrated the capacity of 269 D. vulgaris to route electrons for $\mathrm{Fe}^{\mathrm{III}}$ exclusively through formate.

270 According to the S mass balance in Figure 5, the lactate bottles accumulated more than $40 \%$ 271 of the depleted $\mathrm{SO}_{4}{ }^{2-}$ as sulfite plus some unknown intermediate, probably bisulfide- and/or a 272 trisulfide-DsrC complex that cannot be detected by IC; these metabolites were minimal in the 273 pyruvate bottles. The accumulation of partially reduced S metabolites with lactate indicates that 274 some S-reducing pathways may rely exclusively on $\mathrm{H}_{2}$ oxidation. Full S reduction with pyruvate 275 means that formate was able to fully take over the responsibility of $\mathrm{S}$ reduction when $\mathrm{H}_{2}$ was not 276 normally generated.

\section{Ambient $\mathbf{p H}$ and solid growth duration affected crystallization of biogenic mackinawite}

278 Figure 6 presents the XRD patterns and TEM images of the biogenic solids collected from 279 the bottles in the primary study. They confirm that mackinawite $\left(\mathrm{Fe}_{1+\mathrm{x}} \mathrm{S}\right)$ nanoparticles were the 
280 predominant solid products. The lateral thicknesses of the mackinawite crystallites estimated 281 using XRD and TEM were consistent (Table 1), and they reflected poorer crystallization of 282 biogenic mackinawite with lactate as the electron donor or $\mathrm{Fe}^{\mathrm{III}}$ as the iron source. Pyruvate 283 transformation to acetate decreases the $\mathrm{pH}$ more than does lactate transformation to acetate, 284 because it produces more protons for reducing the same quantity of $\mathrm{SO}_{4}{ }^{2-}$ (stoichiometry in Eqns. 285 S1 and S2 and experimental confirmation in Figs. 1 and 2). Thus, the observed greater 286 crystallization with pyruvate is consistent with a previous study (Zhou et al. 2014a) that revealed 287 that lower $\mathrm{pH}$ accelerated mackinawite crystallization. In addition, lactate experiments with a 288 lag period before $\mathrm{SO}_{4}{ }^{2-}$ reduction shortened the time for mackinawite crystallite growth.

289 Figure 7 presents a 3-dimentional graph to visualize the correlation of biogenic 290 mackinawite size with $\mathrm{pH}$ and the time for crystal growth on basis of 20 sets of experimental 291 data in this study and previous studies (Zhou et al. 2015a, Zhou et al. 2014a). The simulation 292 clearly identifies the synergetic effect of low $\mathrm{pH}$ and longer crystal-growth time for promoting 293 mackinawite crystallization. The underlying mechanism probably is associated with Ostwald 294 ripening that, as illustrated in Figure S1A, states that smaller particles dissolve and re-precipitate 295 on the larger particles as a means to minimize the overall energy (Guilbaud et al. 2010, Luther). 296 Based on Oswald ripening, lower pH speeded up mackinawite dissolution (Fig. S1B), while 297 longer growth time allowed more re-precipitation. 


\section{Discussion}

We propose Figure 8 as a conceptual framework for understanding electron flow from

300 lactate and pyruvate for dissimilatory $\mathrm{SO}_{4}{ }^{2-}$ and $\mathrm{Fe}^{\mathrm{III}}$ reductions by $D$. vulgaris. In short, electron

301 flow from lactate or pyruvate towards $\mathrm{SO}_{4}{ }^{2-}$ reduction is not exclusively governed by only direct,

302 membrane-bound MQ mediation or by indirect, membrane-crossing $\mathrm{H}_{2}$ /formate cycling; rather,

303 electron flow is regulated by the $e^{-}$donor and the presence of another $e^{-}$acceptor (i.e., $\mathrm{Fe}^{\mathrm{III}}$ in our

304 study). Thus, our framework reconciles earlier models that appeared to contradict each other.

305 The following sections and Figures S2 - S6 systematically explain how the experimental results

306 lead to the framework in Figure 8.

\section{Endergonic formation of $\mathrm{H}_{2}$ from lactate for $\mathrm{SO}_{4}{ }^{2-}$ reduction: redundancy or strategy?}

308 Lactate fermentation to pyruvate has a higher half-reaction reduction potential $(-0.19 \mathrm{mV}$

309 (Rabus et al. 2006); Table 2) than reduction of potential $e^{-}$acceptors, including proton to $\mathrm{H}_{2}(-$

$3100.414 \mathrm{mV}$ (Langmuir 1997)) and $\mathrm{SO}_{4}{ }^{2-}$ to sulfide (-0.22 $\mathrm{mV}$ (Rabus et al. 2006)); thus, the

311 processes having electron flow counter to the half-reaction redox potential need to be fueled by

312 pyruvate oxidation to acetyl-CoA, which generates energy that can be coupled with reduction of

313 protons (-0.414 mV (Langmuir 1997)), $\mathrm{CO}_{2}\left(-0.498 \mathrm{mV}\right.$ (Rabus et al. 2006)), or $\mathrm{SO}_{4}{ }^{2-}(-0.432$

$314 \mathrm{mV}$ (Meyer et al. 2013)).

315 The additional energy cost for fermenting lactate to pyruvate became a thermodynamic

316 barrier reflected by longer lag phase, lower biomass yield, and lower substrate utilization rate

317 than pyruvate metabolism (Table 1). Taking the "Ockham's Razor" principle to the

318 thermodynamic perspective (Schönheit et al. 2016, Schoepp-Cothenet et al. 2013), we conclude

319 that, compared to directly delivering electrons through MQ pool for $\mathrm{SO}_{4}{ }^{2-}$ reduction, it is less 
320 efficient for bacteria to invest more energy to form $\mathrm{H}_{2}$ and then recover the energy from $\mathrm{H}_{2}$ for

$321 \mathrm{SO}_{4}{ }^{2-}$ reduction. The reason is that $\mathrm{H}_{2}$ diffusion or electron transport through membrane-bound

322 carriers between the cytoplasm and the periplasm costs additional energy.

323 The fulcrum of the regulation is the $\mathrm{H}_{2}$ concentration, which has to be very low to allow

324 fermentation to proceed. Any "friction" to $\mathrm{H}_{2}$ diffusion to its sink raises the $\mathrm{H}_{2}$ concentration

325 near its point of generation. In some models (Meyer et al. 2013, Walker et al. 2009), $\mathrm{H}_{2}$ is

326 produced only after $\mathrm{SO}_{4}{ }^{2-}$ is depleted or with sulfate-free conditions; $\mathrm{H}_{2}$ accumulation

327 immediately inhibited further metabolism unless the $\mathrm{H}_{2}$ was scavenged by syntrophic partners

328 like methanogens. In contrast, we observed $\mathrm{H}_{2}$ accumulation up to $8 \%$ of the total available

329 electron equivalent in lactate (or $0.06 \mathrm{~atm}$, twice of the proposed inhibitive threshold as reported

330 by Noguera et al. (1998)) during the lag phase of our primary study. We saw that $\mathrm{H}_{2}$ buildup

331 partially inhibited subsequent pyruvate oxidation during the first 20 hours (the first $2 / 3^{\text {rd }}$ of the

332 lag phase), but not lactate-induced $\mathrm{H}_{2}$ production itself, as indicated by accumulation of pyruvate

333 (Figs. 1A-2 and 3A), which otherwise would be rapidly transformed to acetate due to its faster

334 metabolism (Table 1). The underlying inhibition mechanism may be associated with $\mathrm{H}_{2^{-}}$

335 regulated deactivation of pyruvate formate lyase ( $\mathrm{Pfl}$ ) and/or pyruvate:ferredoxin oxidoreductase

336 (Por), as proposed by Figure S4. As $\mathrm{SO}_{4}{ }^{2-}$ reduction provides higher biomass yield than $\mathrm{CO}_{2}$

337 and/or proton reduction (Noguera et al. 1998), this "long-term-investment" strategy would limit

338 the too-rapid diversion of pyruvate-generated electrons towards $\mathrm{CO}_{2}$ or proton reductions before

339 rapid and more energetically profitable $\mathrm{SO}_{4}{ }^{2-}$ reduction was able to be initiated; thus, delaying

340 pyruvate transformation would maximize bacterial growth. 
341 Direct versus indirect $e^{-}$flow for $\mathrm{SO}_{4}{ }^{2-}$ reduction is regulated by $e^{-}$donor

342 In addition to inhibiting pyruvate metabolism, lactate-originated $\mathrm{H}_{2}$ also may regulate the 343 initiation of $\mathrm{SO}_{4}{ }^{2-}$ metabolism: in our study, rapid $\mathrm{SO}_{4}{ }^{2-}$ reduction in lactate bottles was not

344 initiated until dissolved $\mathrm{H}_{2}$ in the liquid phase accumulated up to over 10 fold of the reported $\mathrm{H}_{2}$

345 half-saturation constant at $1.4 \mu \mathrm{M}$ for D. vulgaris (Noguera et al. 1998); when $\mathrm{H}_{2}$ was less, $\mathrm{SO}_{4}{ }^{2-}$

346 reduction was greatly retarded. The metabolic patterns in presence of soluble $\mathrm{Fe}^{\mathrm{III}}$ reduction

347 supported further insight on the pathway regulation. As an $e^{-}$acceptor for D. vulgaris

348 metabolism, soluble $\mathrm{Fe}^{\mathrm{III}}$ is more favorable than $\mathrm{SO}_{4}{ }^{2-}$ because: 1) soluble $\mathrm{Fe}^{\mathrm{III}}$ reduction has a

349 higher half-reaction reduction potential (Table 2); and 2) $\mathrm{Fe}^{\mathrm{III}}$ is able to accept electrons carried

350 by periplasmic TpI $c_{3}$ (Fig. 8 and Fig. S3). Periplasmic Fe ${ }^{\mathrm{III}}$ reduction shortcuts electron flow and

351 eliminates electron delivery back to the cytoplasm for indirect $\mathrm{SO}_{4}{ }^{2-}$ reduction (i.e., the

352 membrane-crossing $\mathrm{H}_{2}$ cycling process). In contrast, the route of direct $\mathrm{SO}_{4}{ }^{2-}$ reduction through

353 membrane-bound MQ mediation is independent from periplasmic Fe ${ }^{\mathrm{III}}$ reduction; thus, it is able

354 to compete for electrons with $\mathrm{Fe}$ III . For this scenario, complete inhibition of $\mathrm{SO}_{4}{ }^{2-}$ reduction until

$355 \mathrm{Fe}^{\mathrm{III}}$ depletion in Lac+Fe ${ }^{\mathrm{III}}$ bottles (B-1 in Fig. 1) suggests that the initiation of $\mathrm{SO}_{4}{ }^{2-}$ reduction

356 was controlled predominantly by the indirect cycling of $\mathrm{H}_{2}$ produced from lactate (as proposed in

357 Fig. S3). In contrast, concomitant $\mathrm{Fe}^{\mathrm{III}}$ and $\mathrm{SO}_{4}{ }^{2-}$ reduction in $\mathrm{Pyr}+\mathrm{Fe}^{\mathrm{III}}$ bottles (B-1 in Fig. 2)

358 underscores that the initiation of $\mathrm{SO}_{4}{ }^{2-}$ reduction was regulated by direct electron flow from 359 pyruvate (as proposed in Figs. S4 and S5).

360 Although the metabolic significance underlying this electron-donor-dependent regulation is 361 not completely clear, its impact on biogenic iron-sulfide was apparent: $\mathrm{H}_{2}$-induced electron flow 362 initiated $\mathrm{SO}_{4}{ }^{2-}$ reduction after long lag phase (B-1 in Fig. 1) or gave full priority to Fe ${ }^{\mathrm{III}}$ reduction 363 (B-1 in Fig. 2). The consequence was a shortened time for iron-sulfide crystallite growth. 


\section{The $\mathrm{TpI} c_{3}$ pool was also essential for completing $\mathrm{SO}_{4}{ }^{2-}$ reduction to $\mathrm{S}^{2-}$.}

365 For $\mathrm{SO}_{4}{ }^{2-}$ reduction, indirect electron flow through $\mathrm{H}_{2}$ or formate cycling was

366 thermodynamically less favorable than through direct MQ mediation. Ideally for energy

367 conservation, the indirect electron flow should have been spontaneously shut off upon initiation

368 of rapid $\mathrm{SO}_{4}{ }^{2-}$ reduction. However, formate accumulated along with electron donor consumption

369 and subsequently was depleted during rapid $\mathrm{SO}_{4}{ }^{2-}$ reduction in all conditions of our study (A-2

370 and B-2 in Figs. 1 and 2). This implies that formate-involved electron transfer was responsible

371 for at least $10 \%$ of $\mathrm{SO}_{4}{ }^{2-}$ reduction. The metabolic significance of maintaining part of $\mathrm{TpI}_{3} 3^{-}$

372 mediated $\mathrm{H}_{2}$ /formate oxidation was further documented in the supplementary study, where $\mathrm{H}_{2}$

373 was stripped out of the headspace. Incomplete $\mathrm{SO}_{4}{ }^{2-}$ reduction when $\mathrm{H}_{2}$ was stripped implies

374 that part of the $\mathrm{SO}_{4}{ }^{2-}$ respiratory pathway relied on $\mathrm{TpI} c_{3}$ activities. For instance, our observation

375 of considerable sulfite accumulation in the absence of $\mathrm{H}_{2}$ (Fig. 5) identifies that $\mathrm{H}_{2}$-induced

376 electron transfer involving the $\mathrm{TpI} c_{3}$ pool is necessary for full reduction. In addition, previous

377 research (Pereira et al. 2011, Santos et al. 2015) proposes that membrane-bound sulfite

378 reductases (DsrMKJOP) transfer electrons from $\mathrm{TpI} c_{3}$ for catalyzing disulfide or trisulfide

379 reduction to sulfide. In our supplementary study, unidentified S species -- possibly the disulfide-

380 and/or trisulfide-DsrC complex -- accumulated in the absence of lactate-originated $\mathrm{H}_{2}$; the

381 phenomenon indicates the indispensable role of $\mathrm{TpI} c_{3}$-involved electron transfer in completing

$382 \mathrm{SO}_{4}{ }^{2-}$ reduction (as proposed in Fig. S6). 


\section{Conclusions}

385 Our study emphasizes the significant effect of the $e^{-}$donor in directly stimulating $\mathrm{SO}_{4}{ }^{2-}$ and $\mathrm{Fe}^{\mathrm{III}}$ 386 reduction and in indirectly controlling the production of desired iron-sulfide nanoparticles. In

387 particular, when $\mathrm{H}_{2}$-induced periplasmic electron flow gave greater priority to $\mathrm{Fe}^{\mathrm{III}}$ reduction 388 over membrane-crossing electron acceptation by $\mathrm{SO}_{4}{ }^{2-}$ as the main route of lactate-mediated $389 \mathrm{SO}_{4}{ }^{2-}$ reduction, the longer lag phase before sulfate reduction shortened the time for iron-sulfide 390 crystallite growth and led to smaller mackinawite $\left(\mathrm{Fe}_{1+x} \mathrm{~S}\right)$ nanocrystallites. Overall, the study 391 suggests that the $e^{-}$donor provides a practical tool to regulate and optimize SRB-predominant 392 bioremediation systems. For example, FeS can be used to retard re-oxidation of immobilized 393 uraninite. Having FeS with controllable quality is an advantage, and our results point out that $394 \mathrm{Fe}^{\mathrm{III}}$ is a better iron source to maintain FeS nanoparticles with higher redox reactivity. A second 395 example is bioremediating AMD containing high concentrations of $\mathrm{Fe}^{\mathrm{III}}$ and $\mathrm{SO}_{4}{ }^{2-}$. Pyruvate is a 396 better electron donor for bio-stimulation for two reasons. First, pyruvate accelerates the overall 397 process by enabling $\mathrm{SO}_{4}{ }^{2-}$ reduction concomitant with $\mathrm{Fe}^{\mathrm{III}}$ reduction. Second, pyruvate saves 398 operating costs because the same amount of sulfide is produced with $45 \%$ the chemical cost 399 compared to lactate (details in ESM) to immobilize hazardous soluble metals (e.g., $\mathrm{Pb}^{2+}, \mathrm{Cd}^{2+}$, 400 and $\mathrm{Mn}^{2+}$ ). 


\section{Acknowledgements}

402 We express gratitude to the Office of Science, U.S. Department of Energy, Grant No. DE403 FG02-09ER64803, for supporting this research. We gratefully acknowledge the use of facilities 404 supervised by Thomas Groy at the Department of Chemistry and biochemistry, and by Karl 405 Weiss

406 in the LeRoy Eyring Center for Solid State Science, both at Arizona State University. 


\section{References}

408

409

410

411

412

413

414

415

416

417

418

419

420

421

422

423

424

425

426

427

428

429

430

431

432

433

434

435

436

437

438

439

440

441

442

443

444

445

446

447

448

449

Abdelouas, A., Lutze, W. and Nuttall, H.E. (1999) Oxidative dissolution of uraninite precipitated on Navajo sandstone. Journal of Contaminant Hydrology 36(3-4), 353-375.

Bai, H., Kang, Y., Quan, H., Han, Y., Sun, J. and Feng, Y. (2013) Treatment of acid mine drainage by sulfate reducing bacteria with iron in bench scale runs. Bioresour Technol 128, 818-822.

Bi, Y. and Hayes, K.F. (2014) Nano-FeS inhibits $\mathrm{UO}_{2}$ reoxidation under varied oxic conditions. Environmental Science \& Technology 48, 632-640.

Bi, Y., Hyun, S., Kukkadapu, R.K. and Hayes, K.F. (2013) Oxidative dissolution of $\mathrm{UO}_{2}$ in a simulated groundwater containing synthetic nanocrystalline mackinawite. Geochimica Et Cosmochimica Acta 102, 175-190.

Carpenter, J., Bi, Y. and Hayes, K.F. (2015) Influence of iron sulfides on abiotic oxidation of $\mathrm{UO}_{2}$ by nitrite and dissolved oxygen in natural sediments. Environmental Science \& Technology 49(2), 1078-1085.

Chung, J., Nerenberg, R. and Rittmann, B.E. (2006) Bioreduction of selenate using a hydrogenbased membrane biofilm reactor. Environmental Science \& Technology 40(5), 1664-1671.

Elias, D.A., Suflita, J.M., McInerney, M.J. and Krumholz, L.R. (2004) Periplasmic cytochrome $c_{3}$ of Desulfovibrio vulgaris is directly involved in $\mathrm{H}_{2}$-mediated metal but not sulfate reduction. Applied and Environmental Microbiology 70(1), 413-420.

Fredrickson, J.K. and Gorby, Y.A. (1996) Environmental Processes Mediated by Iron-Reducing Bacteria. Current Opinion in Biotechnology 7(3), 287-294.

Fredrickson, J.K., Zachara, J.M., Kennedy, D.W., Duff, M.C., Gorby, Y.A., Li, S.M.W. and Krupka, K.M. (2000) Reduction of U(VI) in Goethite (alpha-FeOOH) Suspensions by a Dissimilatory Metal-Reducing Bacterium. Geochimica Et Cosmochimica Acta 64(18), 30853098.

Guilbaud, R., Butler, I.B., Ellam, R.M. and Rickard, D. (2010) Fe isotope exchange between $\mathrm{Fe}(\mathrm{II})_{\mathrm{aq}}$ and nanoparticulate mackinawite $\left(\mathrm{FeS}_{\mathrm{m}}\right)$ during nanoparticle growth. Earth and Planetary Science Letters 300(1), 174-183.

Heidelberg, J.F., Seshadri, R., Haveman, S.A., Hemme, C.L., Paulsen, I.T., Kolonay, J.F., Eisen, J.A., Ward, N., Methe, B., Brinkac, L.M., Daugherty, S.C., Deboy, R.T., Dodson, R.J., Durkin, A.S., Madupu, R., Nelson, W.C., Sullivan, S.A., Fouts, D., Haft, D.H., Selengut, J., Peterson, J.D., Davidsen, T.M., Zafar, N., Zhou, L.W., Radune, D., Dimitrov, G., Hance, M., Tran, K., Khouri, H., Gill, J., Utterback, T.R., Feldblyum, T.V., Wall, J.D., Voordouw, G. and Fraser, C.M. (2004) The genome sequence of the anaerobic, sulfate-reducing bacterium Desulfovibrio vulgaris Hildenborough. Nature Biotechnology 22(5), 554-559.

Huo, Y.-C., Li, W.-W., Chen, C.-B., Li, C.-X., Zeng, R., Lau, T.-C. and Huang, T.-Y. (2016) Biogenic FeS accelerates reductive dechlorination of carbon tetrachloride by Shewanella putrefaciens CN32. Enzyme and Microbial Technology 95, 236-241.

Karamanev, D., Nikolov, L. and Mamatarkova, V. (2002) Rapid simultaneous quantitative determination of ferric and ferrous ions in drainage waters and similar solutions. Minerals Engineering 15(5), 341-346.

Keller, K. and Wall, J. (2011) Genetics and Molecular Biology of the Electron Flow for Sulfate Respiration in Desulfovibrio. Frontiers In Microbiology 2(135), 1-17. 
Keller, K.L., Rapp-Giles, B.J., Semkiw, E.S., Porat, I., Brown, S.D. and Wall, J.D. (2014) New model for electron flow for sulfate reduction in Desulfovibrio alaskensis G20. Applied and Environmental Microbiology 80(3), 855-868.

Langmuir, D. (1997) Aqueous Environmental Geochemistry, Prentice Hall, Upper Saddle River, NJ, USA.

Luther, G.W. Metal Sulfides in the Environment and in Bioinorganic Chemistry. Inorganic Chemistry for Geochemistry and Environmental Sciences: Fundamentals and Applications, 390-405.

Meyer, B., Kuehl, J., Deutschbauer, A.M., Price, M.N., Arkin, A.P. and Stahl, D.A. (2013) Variation among Desulfovibrio species in electron transfer systems used for syntrophic growth. Journal of Bacteriology 195(5), 990-1004.

Moyes, L.N., Parkman, R.H., Charnock, J.M., Vaughan, D.J., Livens, F.R., Hughes, C.R. and Braithwaite, A. (2000) Uranium uptake from aqueous solution by interaction with goethite, lepidocrocite, muscovite, and mackinawite: An X-ray absorption spectroscopy study. Environmental Science \& Technology 34(6), 1062-1068.

Noguera, D.R., Brusseau, G.A., Rittmann, B.E. and Stahl, D.A. (1998) A unified model describing the role of hydrogen in the growth of Desulfovibrio vulgaris under different environmental conditions. Biotechnology and Bioengineering 59(6), 732-746.

Oliveira, T.F., Vonrhein, C., Matias, P.M., Venceslau, S.S., Pereira, I.A. and Archer, M. (2008) The crystal structure of Desulfovibrio vulgaris dissimilatory sulfite reductase bound to DsrC provides novel insights into the mechanism of sulfate respiration. Journal of Biological Chemistry 283(49), 34141-34149.

Pankhania, I.P., Spormann, A.M., Hamilton, W.A. and Thauer, R.K. (1988) Lactate conversion to acetate, $\mathrm{CO}_{2}$ and $\mathrm{H}_{2}$ in cell suspensions of Desulfovibrio vulgaris (Marburg): indications for the involvement of an Energy driven reaction. Archives of Microbiology 150(1), 26-31.

Peck, H.D., Legall, J., Lespinat, P.A., Berlier, Y. and Fauque, G. (1987) A Direct Demonstration of Hydrogen Cycling by Desulfovibrio-Vulgaris Employing Membrane-Inlet MassSpectrometry. FEMS Microbiology Letters 40(2-3), 295-299.

Pereira, I.A.C., Ramos, A.R., Grein, F., Marques, M.C., da Silva, S.M. and Venceslau, S.S. (2011) A comparative genomic analysis of energy metabolism in sulfate reducing bacteria and archaea. Frontiers In Microbiology 2(69), 1-22.

Pieulle, L., Magro, V. and Hatchikian, E.C. (1997) Isolation and Analysis of the Gene Encoding the Pyruvate-Ferredoxin Oxidoreductase of Desulfovibrio africanus, Production of the Recombinant Enzyme in Escherichia coli, and Effect of Carboxy-terminal Deletions on Its Stability. Journal of Bacteriology 179(18), 5684-5692.

Rabus, R., Hansen, T.A. and Widdel, F. (2006) The prokaryotes, pp. 659-768, Springer.

Ramos, A.R., Keller, K.L., Wall, J.D. and Pereira, I.A.C. (2012) The membrane QmoABC complex interacts directly with the dissimilatory adenosine 5-phosphosulfate reductase in sulfate reducing bacteria. Frontiers In Microbiology 3, 137.

Rittmann, B.E. and McCarty, P.L. (2001) Environmental biotechnology: principles and applications, McGraw-Hill, Boston.

Sánchez-Andrea, I., Sanz, J.L., Bijmans, M.F. and Stams, A.J. (2014) Sulfate reduction at low pH to remediate acid mine drainage. Journal of Hazardous Materials 269, 98-109.

Sani, R.K., Peyton, B.M., Amonette, J.E. and Geesey, G.G. (2004) Reduction of uranium(VI) under sulfate-reducing conditions in the presence of Fe(III)-(hydr)oxides. Geochimica Et 
Cosmochimica Acta 68(12), 2639-2648.

Santos, A.A., Venceslau, S.S., Grein, F., Leavitt, W.D., Dahl, C., Johnston, D.T. and Pereira, I.A. (2015) A protein trisulfide couples dissimilatory sulfate reduction to energy conservation. Science 350(6267), 1541-1545.

Schönheit, P., Buckel, W. and Martin, W.F. (2016) On the origin of heterotrophy. Trends in microbiology 24(1), 12-25.

Schoepp-Cothenet, B., van Lis, R., Atteia, A., Baymann, F., Capowiez, L., Ducluzeau, A.-L., Duval, S., ten Brink, F., Russell, M.J. and Nitschke, W. (2013) On the universal core of bioenergetics. Biochimica et Biophysica Acta (BBA)-Bioenergetics 1827(2), 79-93.

Venceslau, S.S., Lino, R.R. and Pereira, I.A. (2010) The Qrc membrane complex, related to the alternative complex III, is a menaquinone reductase involved in sulfate respiration. Journal of Biological Chemistry 285(30), 22774-22783.

Voordouw, G. (2002) Carbon monoxide cycling by Desulfovibrio vulgaris Hildenborough. Journal of Bacteriology 184(21), 5903-5911.

Walker, C.B., He, Z., Yang, Z.K., Ringbauer, J.A., He, Q., Zhou, J., Voordouw, G., Wall, J.D., Arkin, A.P. and Hazen, T.C. (2009) The electron transfer system of syntrophically grown Desulfovibrio vulgaris. Journal of Bacteriology 191(18), 5793-5801.

Zachara, J.M., Fredrickson, J.K., Smith, S.C. and Gassman, P.L. (2001) Solubilization of Fe(III) oxide-bound trace metals by a dissimilatory $\mathrm{Fe}(\mathrm{III})$ reducing bacterium. Geochimica Et Cosmochimica Acta 65(1), 75-93.

Zhao, H.P., Ilhan, Z.E., Ontiveros-Valencia, A., Tang, Y.N., Rittmann, B.E. and KrajmalnikBrown, R. (2013a) Effects of multiple electron acceptors on microbial interactions in a hydrogen-based biofilm. Environmental Science \& Technology 47(13), 7396-7403.

Zhao, H.P., Ontiveros-Valencia, A., Tang, Y.N., Kim, B.O., Ilhan, Z.E., Krajmalnik-Brown, R. and Rittrnann, B. (2013b) Using a two-stage hydrogen-based membrane biofilm reactor (MBfR) to achieve complete perchlorate reduction in the presence of nitrate and sulfate. Environmental Science \& Technology 47(3), 1565-1572.

Zhao, H.P., Ontiveros-Valencia, A., Tang, Y.N., Kim, B.O., VanGinkel, S., Friese, D., Overstreet, R., Smith, J., Evans, P., Krajmalnik-Brown, R. and Rittmann, B. (2014) Removal of multiple electron acceptors by pilot-scale, two-stage membrane biofilm reactors. Water Research 54, 115-122.

Zhou, C., Liu, Z., Pataranutaporn, P., Vannela, R., Hayes, K.F. and Rittmann, B.E. (2015a) Biogenic nano-particulate iron-sulfide produced through sulfate and Fe (III)-(hydr)oxide reductions was enhanced by pyruvate as the electron donor. RSC Advances 5(122), 100750100761.

Zhou, C., Liu, Z., Pataranutaporn, P., Vannela, R., Hayes, K.F. and Rittmann, B.E. (2015b) Biogenic nano-particulate iron-sulfide produced through sulfate and Fe(III)-(hydr)oxide reductions was enhanced by pyruvate as the electron donor. RSC Advances 5(122), 100750100761.

Zhou, C., Vannela, R., Hayes, K.F. and Rittmann, B.E. (2014a) Effect of growth conditions on microbial activity and iron-sulfide production by Desulfovibrio vulgaris. Journal of Hazardous Materials 272, 28-35.

Zhou, C., Vannela, R., Hyun, S.P., Hayes, K.F. and Rittmann, B.E. (2014b) Growth of Desulfovibrio vulgaris when respiring U(VI) and characterization of biogenic uraninite. Environmental Science \& Technology 48(12), 6928-6937. 


\section{TABLES}

Table 1. Kinetic and stoichiometric parameters estimated from the experimental data, and mackinawite crystallite size estimated from XRD and TEM characterization

\begin{tabular}{|c|c|c|c|c|c|c|c|c|c|}
\hline & \multicolumn{5}{|c|}{ Kinetics } & \multicolumn{2}{|c|}{ Mackinawite (XRD) } & \multicolumn{2}{|c|}{ Mackinawite (TEM) } \\
\hline & $\begin{array}{c}\boldsymbol{Y}_{\mathbf{o b s}}{ }^{a} \\
\left(\mathrm{~g} / e^{-}-\mathrm{eq}\right)\end{array}$ & $\boldsymbol{f}_{\mathrm{s}, \mathrm{obs}}{ }^{b}$ & $\begin{array}{c}\boldsymbol{\mu}_{\max }{ }^{c} \\
\left(\mathrm{~d}^{-1}\right)\end{array}$ & $\begin{array}{c}\boldsymbol{r}_{\text {max, sulfate }}{ }^{d} \\
(\mathrm{mM} / \text { day })\end{array}$ & $\begin{array}{c}\boldsymbol{q}_{\max }{ }^{e} \\
\left(e^{-}-\mathrm{eq} / \mathrm{g} / \mathrm{d}\right)\end{array}$ & $\begin{array}{c}\boldsymbol{F} \boldsymbol{W H} \boldsymbol{M}^{f} \\
\text { (radiance) }^{f}\end{array}$ & $\begin{array}{c}\text { thickness } \\
(\mathrm{nm})\end{array}$ & $\begin{array}{c}d \text {-spacing } \\
\text { (§) }\end{array}$ & $\begin{array}{c}\text { Dimension } \\
(\mathrm{nm})\end{array}$ \\
\hline $\mathrm{Lac}+\mathrm{Fe}^{\mathrm{II}}$ & $1.2 \pm 0.5$ & $0.20 \pm 0.03$ & $\mathbf{3 . 8} \pm 0.7$ & $\mathbf{3 . 1} \pm 0.1$ & $\mathbf{1 . 3} \pm 0.1$ & $\mathbf{0 . 8} \pm 0.0$ & $\mathbf{1 0 . 1} \pm 0.6$ & - & $\mathbf{1 4 . 1} \pm 7.8$ \\
\hline $\mathrm{Lac}+\mathrm{Fe}^{\mathrm{III}}$ & $1.0 \pm 0.2$ & $\mathbf{0 . 2 0} \pm 0.02$ & $3.4 \pm 0.8$ & $3.2 \pm 0.2$ & $1.5 \pm 0.2$ & $2.7 \pm 0.1$ & $\mathbf{3 . 1} \pm 0.3$ & $5.2 \pm 0.1$ & $3.6 \pm 0.7$ \\
\hline $\mathrm{Pyr}+\mathrm{Fe}^{\mathrm{II}}$ & $\mathbf{1 . 5} \pm 0.9$ & $\mathbf{0 . 2 8} \pm 0.03$ & $4.0 \pm 1.2$ & $3.7 \pm 1.0$ & $\mathbf{1 . 5} \pm 0.3$ & $\mathbf{0 . 4} \pm 0.0$ & $20.6 \pm 0.9$ & - & $19.9 \pm 4.4$ \\
\hline $\mathrm{Pyr}+\mathrm{Fe}^{\mathrm{III}}$ & $1.6 \pm 0.3$ & $\mathbf{0 . 2 9} \pm 0.01$ & $4.2 \pm 1.6$ & $\mathbf{3 . 4} \pm 0.8$ & $\mathbf{1 . 0} \pm 0.0$ & $\mathbf{1 . 5} \pm 0.1$ & $\mathbf{5 . 4} \pm 0.6$ & $\mathbf{5 . 3} \pm 0.2$ & $4.1 \pm 0.8$ \\
\hline
\end{tabular}

${ }^{a} Y_{\mathrm{obs}}$ is the apparent yield coefficients. $Y_{\mathrm{obs}}=f_{s}^{\theta}\left(M_{c} \mathrm{~g}\right.$ cells $/ \mathrm{mol}$ cells $) /\left(n_{e} e^{-}\right.$-eq $/ \mathrm{mol}$ cells $)$, where $M_{c}=$ is the empirical formula weight of cells, ne is the number of electron equivalents in an empirical mole of cells. ${ }^{b} f_{\mathrm{s} \text {, obs }}$ is the apparent proportion electrons initially transferred into microbial cells. ${ }^{c} \mu_{\max }$ is the maximum specific growth rate. $\mu=\mathrm{d} x /(x \mathrm{~d} t) \approx \ln \left(x_{2} / x_{1}\right) /\left(t_{2}-t_{1}\right)$, where $x$ is the biomass concentration and $t$ is the time. ${ }^{d} r_{\text {max, sulfate }}$ is the maximum utilization rate of sulfate. $r=-q S x /(K+S)$, where $q$ is the maximum specific rate of sulfate of sulfate utilization, $K$ is the concentration giving one-half the maximum rate, and $S$ is the sulfate concentration. ${ }^{e} q_{\text {max }}$ is the maximum specific rate of sulfate of sulfate utilization. $q \approx\left(S_{2}-S_{1}\right) /\left(x_{2}-x_{1}\right) /\left(t_{2}-t_{1}\right) .{ }^{f} F W H M$ is the full-width at half-maximum. ${ }^{g}$ $d$-spacing is the crystal plane spacing of mackinawite crystallite. 
Table 2. Values of theoretical redox potential $\left(\mathrm{E}_{\mathrm{h}}\right)$ at neutral $\mathrm{pH}$ and $25^{\circ} \mathrm{C}$ for coupled reduction-oxidation reactions involved in this study.

\begin{tabular}{lll}
\hline \multicolumn{1}{c}{ Coupled Reaction } & $\boldsymbol{E h}(\mathrm{V})$ & \multicolumn{1}{c}{ Reference } \\
\hline acetyl-CoA $+\mathrm{CO}_{2}+2 e^{-} \rightarrow$ pyruvate & -0.498 & Rabus et al. (2006) \\
acetyl-CoA + formate $\rightarrow$ pyruvate & -0.432 & Meyer et al. (2013) \\
$\mathrm{Fd}_{\text {ox }}+e^{-} \rightarrow \mathrm{Fd}_{\text {red }}$ & -0.420 & Thauer et al. (2007) \\
acetyl-CoA $+\mathrm{CO}_{2}+\mathrm{H}_{2} \rightarrow$ pyruvate & -0.414 & Meyer et al. (2013) \\
$\mathrm{H}^{+}+e^{-} \rightarrow 1 / 2 \mathrm{H}_{2}$ & -0.414 & Langmuir (1997) \\
cytochrome $c_{3}$ ox/red & -0.290 & Yagi and Maruyama (1971) \\
$\mathrm{SO}_{4}{ }^{2-}+8 e^{-} \rightarrow \mathrm{S}^{2-}$ & -0.220 & Rabus et al. (2006) \\
$\mathrm{Pyruvate}^{2-} 2 e^{-} \rightarrow$ lactate & -0.190 & Rabus et al. (2006) \\
$\mathrm{Fe}^{\mathrm{III}}-\mathrm{Cit}+e^{-} \rightarrow \mathrm{Fe}-\mathrm{Cit}$ & +0.372 & Thamdrup (2000) \\
$\mathrm{Fe}^{3+}+e^{-} \rightarrow \mathrm{Fe}^{2+}(\mathrm{pH}<2)$ & +0.772 & Brock et al. (1994); Thauer et al. (1977) \\
\hline
\end{tabular}


FIGURES

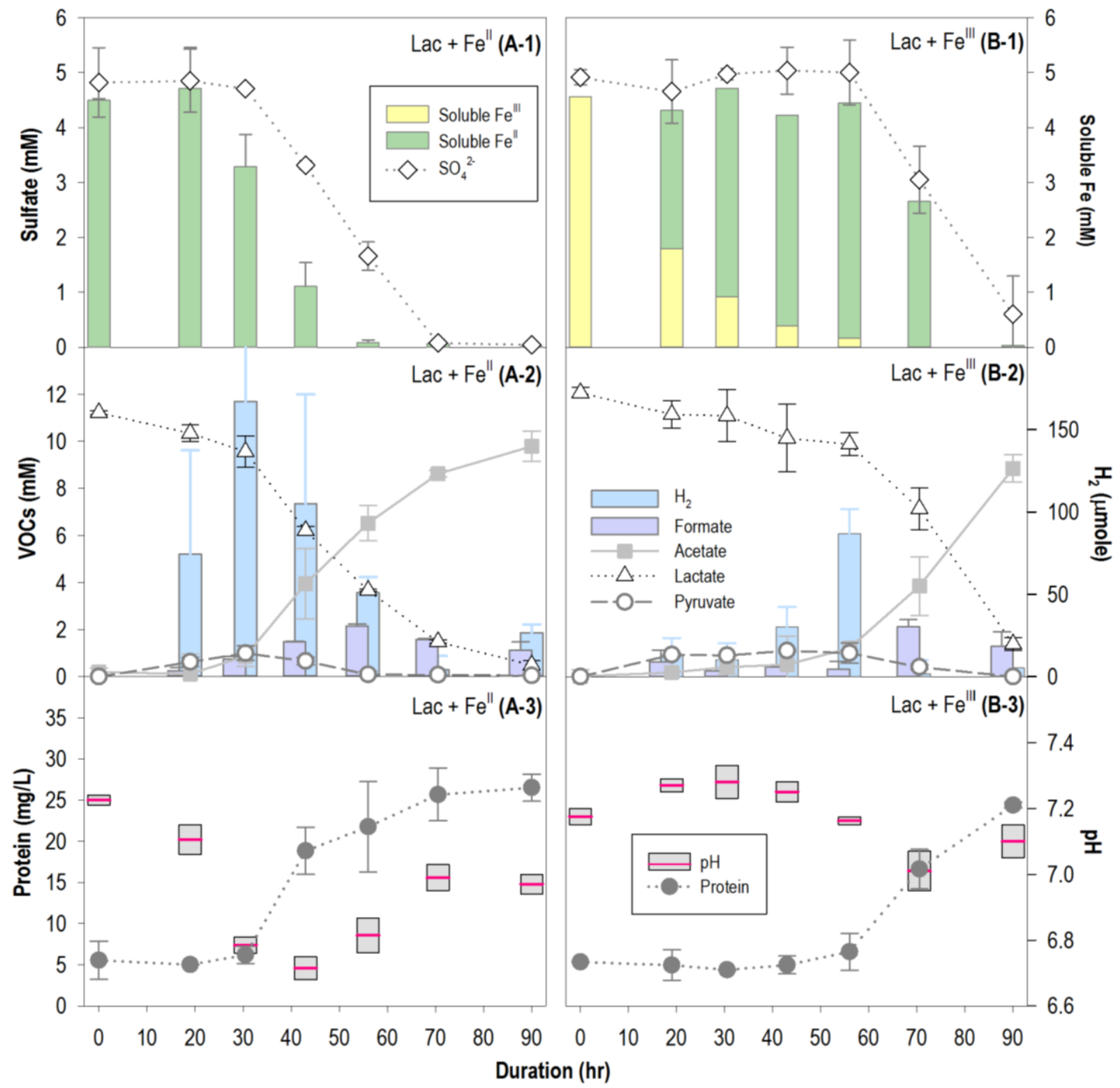

Figure 1. Profiles of $\mathrm{pH}$, substrate, metabolite, and protein concentrations in the main study with lactate as the sole electron donor. Error bars represent standard deviation values. 


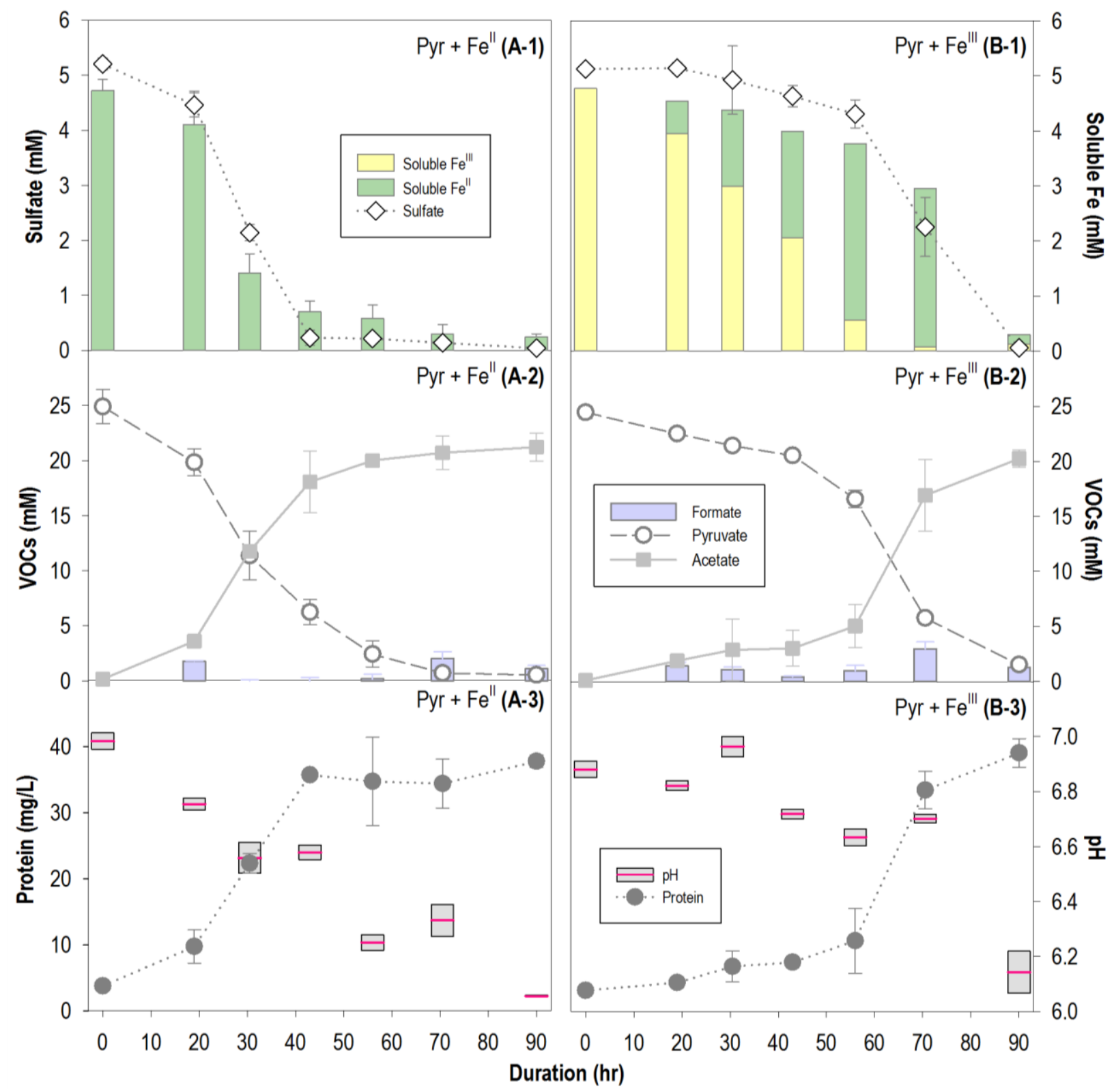

Figure 2. Profiles of $\mathrm{pH}$, substrate, metabolite, and protein concentrations in the main study with pyruvate as the sole electron donor. Error bars represent standard deviation values. 


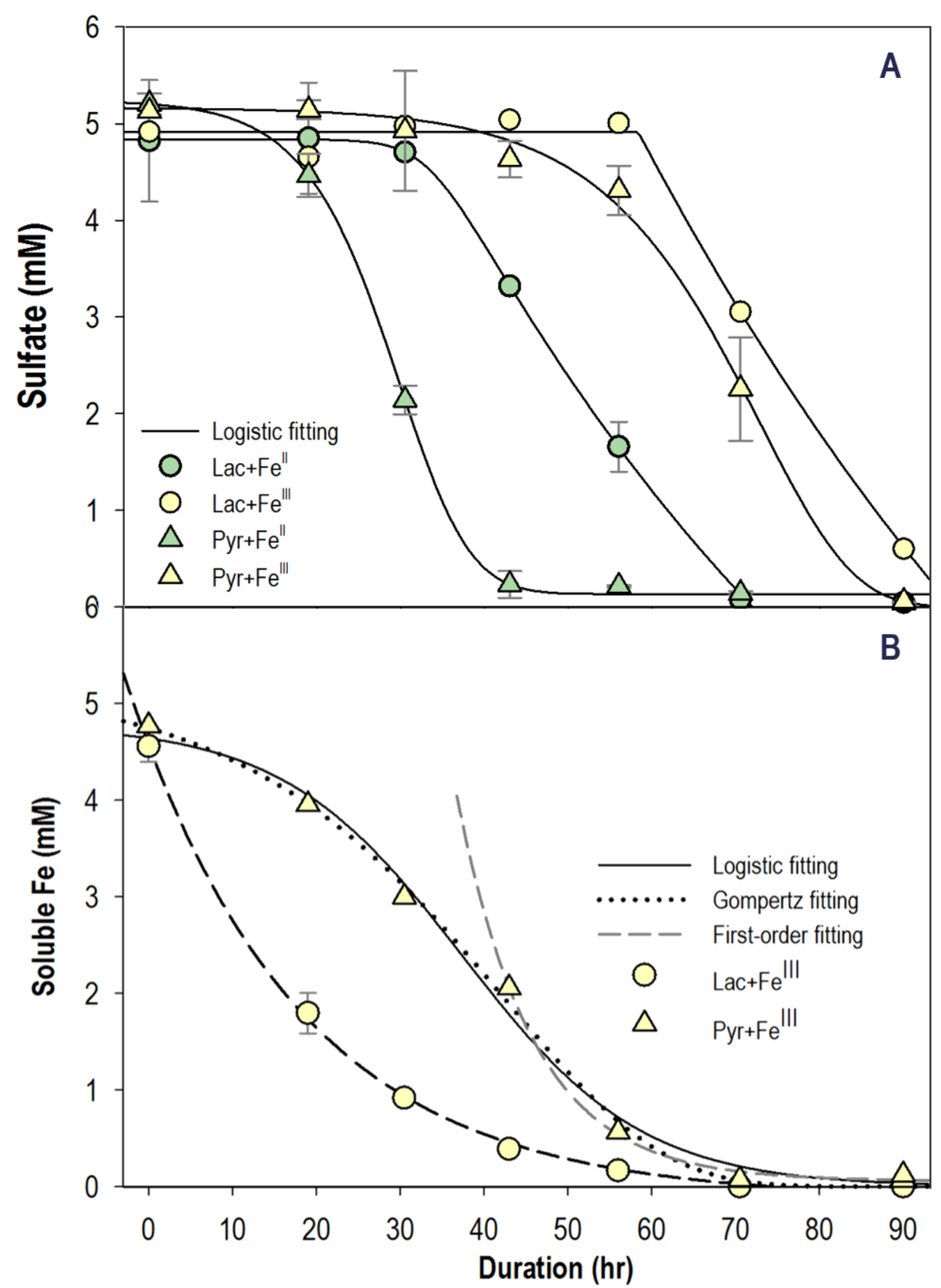

Figure 3. (A) Fitting of experimental sulfate concentration changes in $\mathrm{Lac}+\mathrm{Fe}^{\mathrm{II}}$, $\mathrm{Lac}+\mathrm{Fe}^{\mathrm{III}}$, $\mathrm{Pyr}+\mathrm{Fe}^{\mathrm{II}}$, and $\mathrm{Pyr}+\mathrm{Fe}^{\mathrm{III}}$ using the logistic decay model $\left(\mathrm{R}^{2}=0.9959,0.9971,0.9995\right.$, and 0.9971 , respectively). (B) Fitting of experimental $\mathrm{Fe}^{\mathrm{III}}$ concentration changes in $\mathrm{Lac}+\mathrm{Fe}^{\mathrm{III}}$ using the exponential decay model $\left(\mathrm{R}^{2}=0.9992\right)$; and in $\mathrm{Pyr}+\mathrm{Fe}^{\mathrm{III}}$ using the logistic and the Gompertz decay models for all data $\left(\mathrm{R}^{2}=0.9984\right.$ and 0.9988 , respectively) and the exponential decay model for the data during the last 50 hours $\left(\mathrm{R}^{2}=0.9960\right)$. 

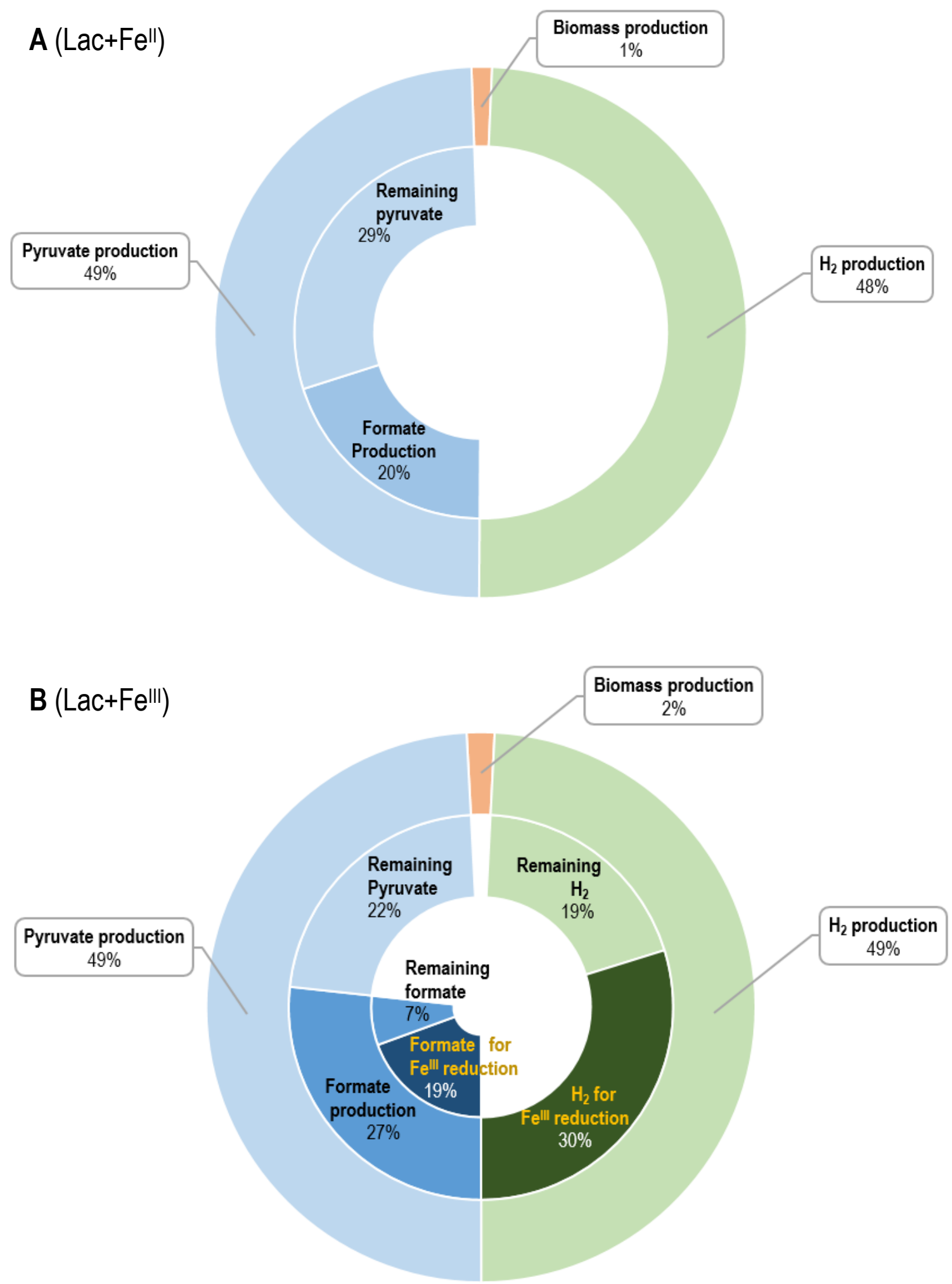

Figure 4. Fates of electron flow from lactate before $\mathrm{SO}_{4}{ }^{2-}$ reduction during the first 30 hours in Lac+Fe ${ }^{\text {II }}$ bottles (A) and first 56 hours in Lac+Fe ${ }^{\mathrm{III}}$ bottles (B). Details of the calculation steps are provided in the SI. 


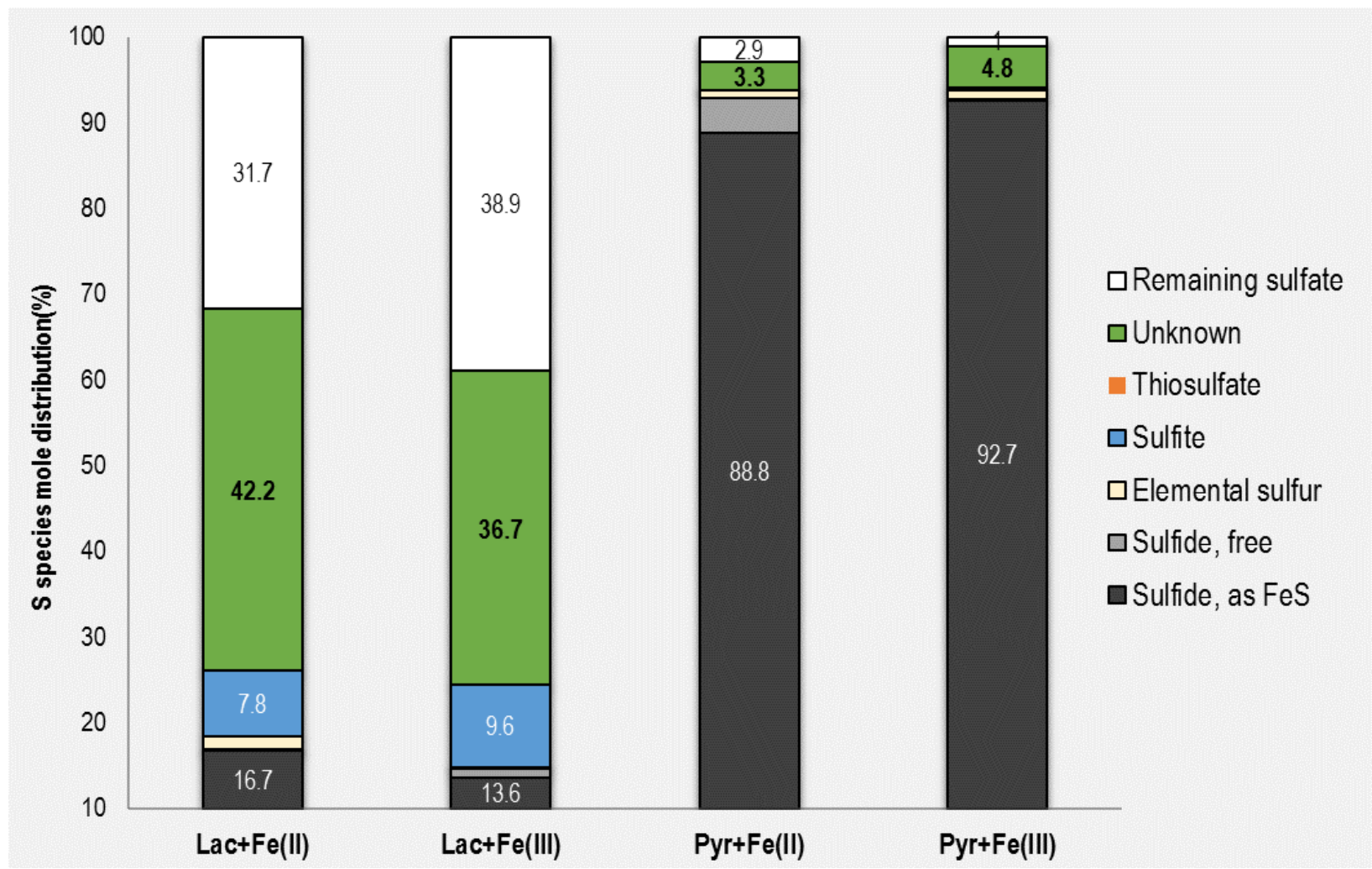

Figure 5. Mole distribution of sulfur species for the four different conditions at the end (90 hours) of the supplementary study. 

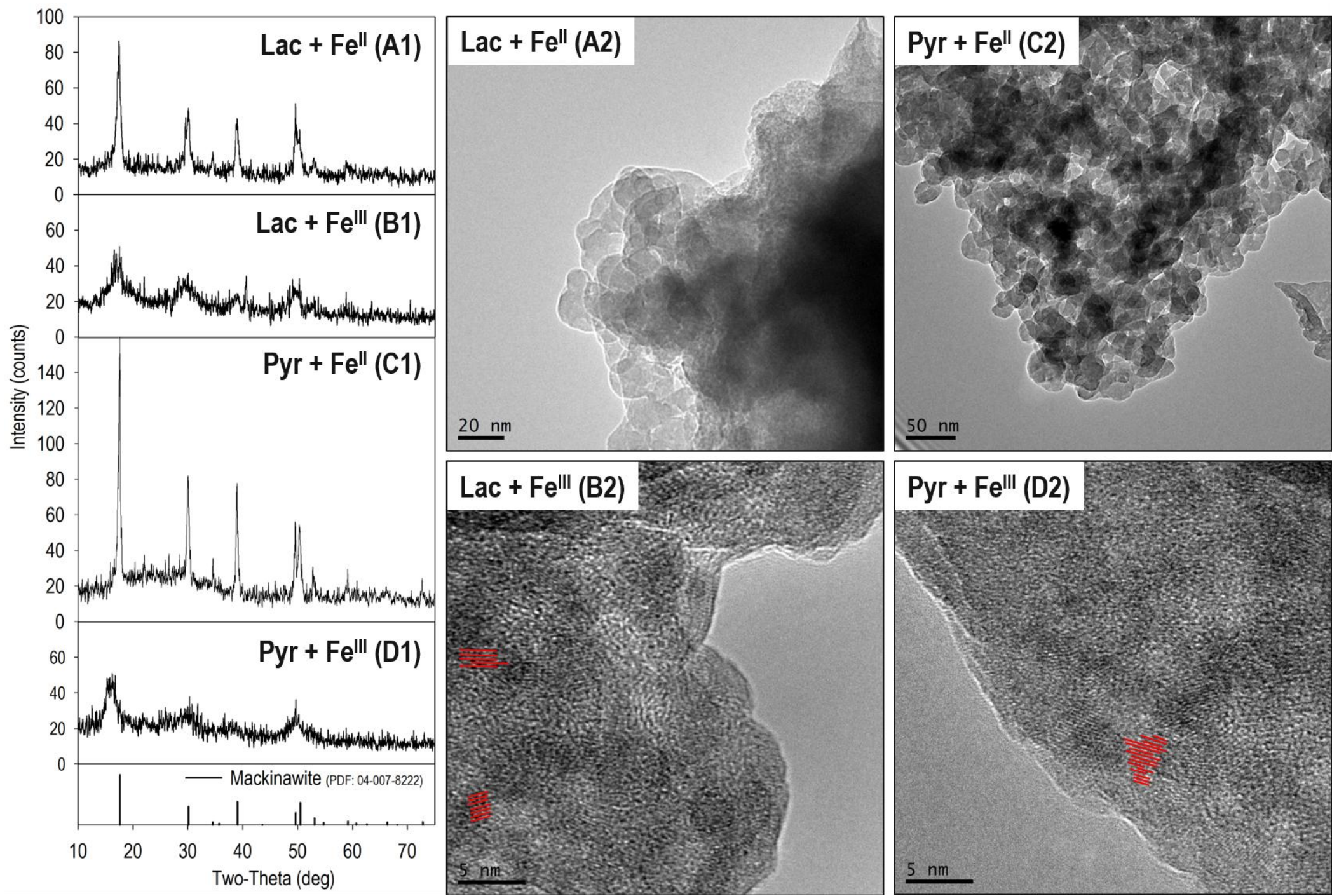

Figure 6. XRD patterns (A1-D1) and TEM images (A2-D2) of solids separated from bottles in the main study identified in the graph. The red lines in the TEM images represent examples of lattice fringes featuring average spacing of $5.3 \pm 0.2 \AA$ corresponding to $d$-spacing of (001) planes of mackinawite. 


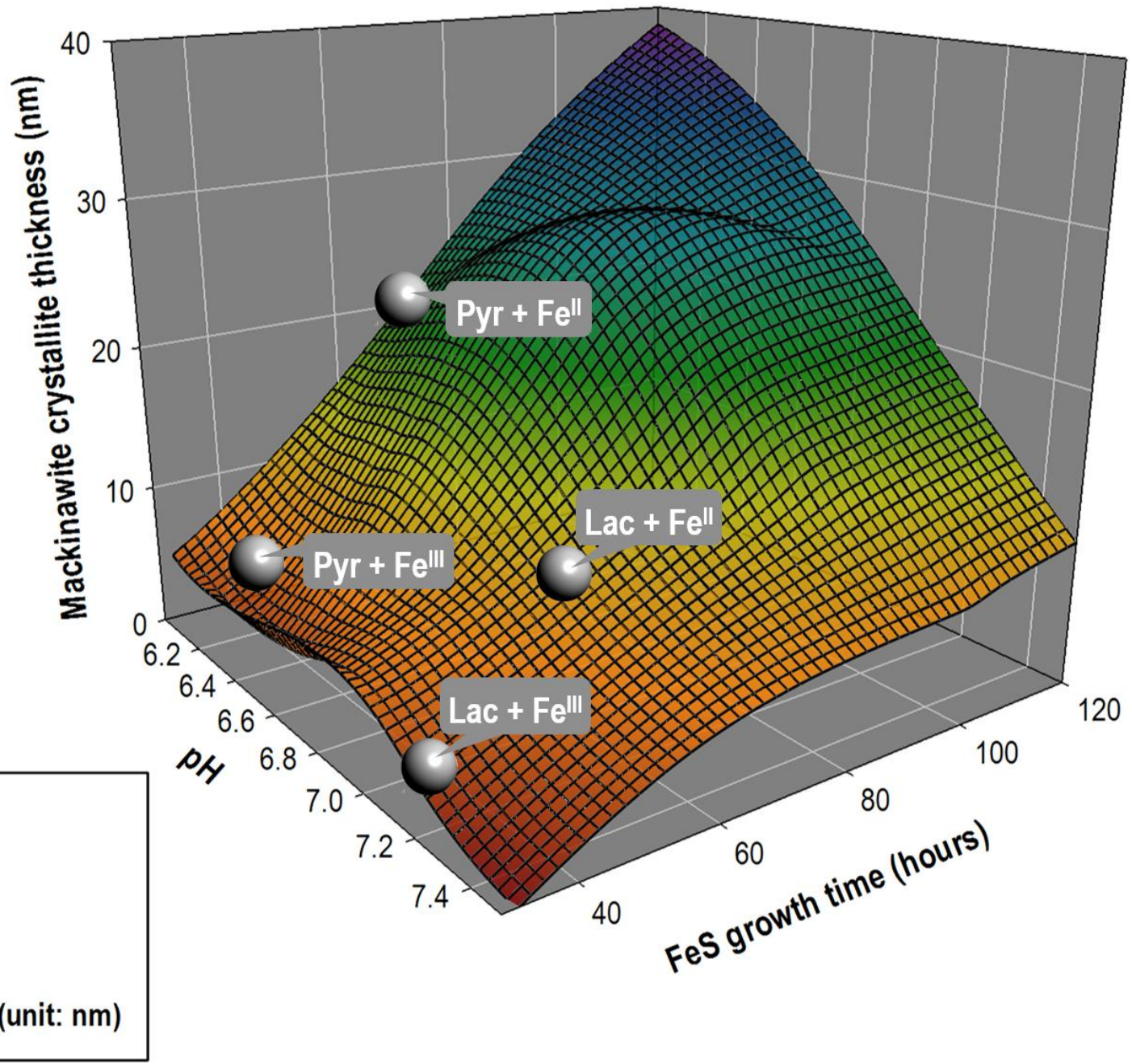

Figure 7. 3D simulation of biogenic mackinawite crystallite thickness as a function of $\mathrm{pH}$ and growth time, based on experimental data from this and previous studies. The four balls highlight the mackinawite produced by $D$. vulgaris under the four conditions in this study. The growth time was measured from the beginning of rapid sulfate reduction to the end of incubation (solids separation). 


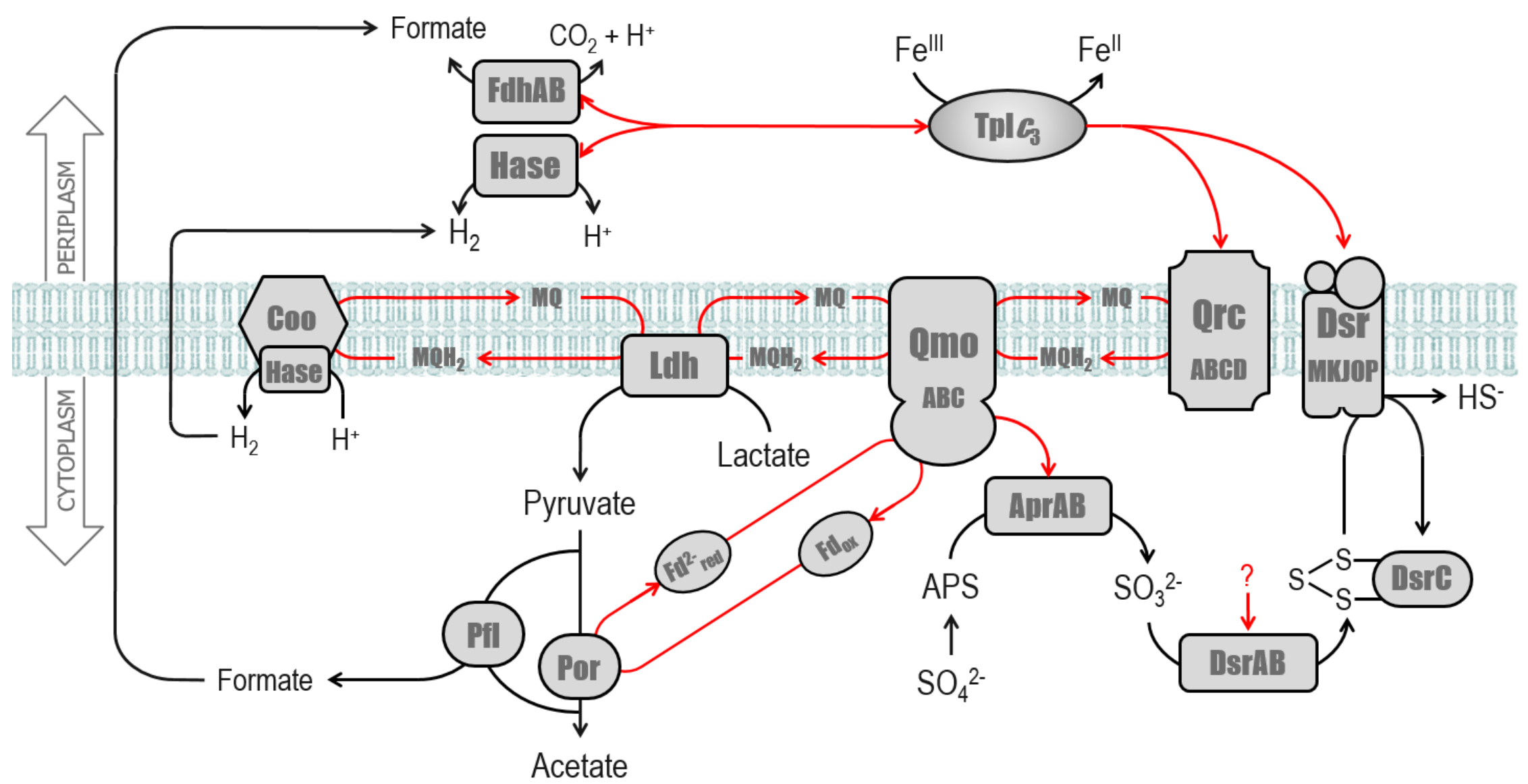

Figure 8. Comprehensive model of electron flow from lactate or pyruvate for dissimilatory sulfate and $\mathrm{Fe}^{\mathrm{III}}$ reductions by $D$. vulgaris. Red arrows represent electron flow, and black arrows represent substrate transformation. APS, Adenosine-5'phosphosulfate; ApsAB, APS hydrogenases; Coo Hase, CO-induced membrane-bound hydrogenase; DsrAB and $D s r C$, cytoplasmic sulfite reductases; DsrMKJOP, membrane-bound sulfite reductases; $F d^{2-}$ red and $F d_{d o x}$, reduced and oxidized ferredoxin, respectively; FdhAB, formate dehydrogenases; Hase, periplasmic hydrogenases; Ldh, lactate dehydrogenase; $M Q$, menaquinone; $\mathrm{MQH}_{2}$, menaquinol; $\mathrm{Pfl}$, pyruvate formate lyase; Por, pyruvate:ferredoxin oxidoreductase; $Q m o A B C$, quinone-interacting membrane-bound oxidoreductases; $Q r c A B C D$, TpI $c_{3}: \mathrm{MQ}$ oxidoreductases; $T p I c_{3}$, type I tetraheme cytochrome $c_{3}$. The separate electron-flow pathways are illustrated in Figures S2 - S6 in ESM. 


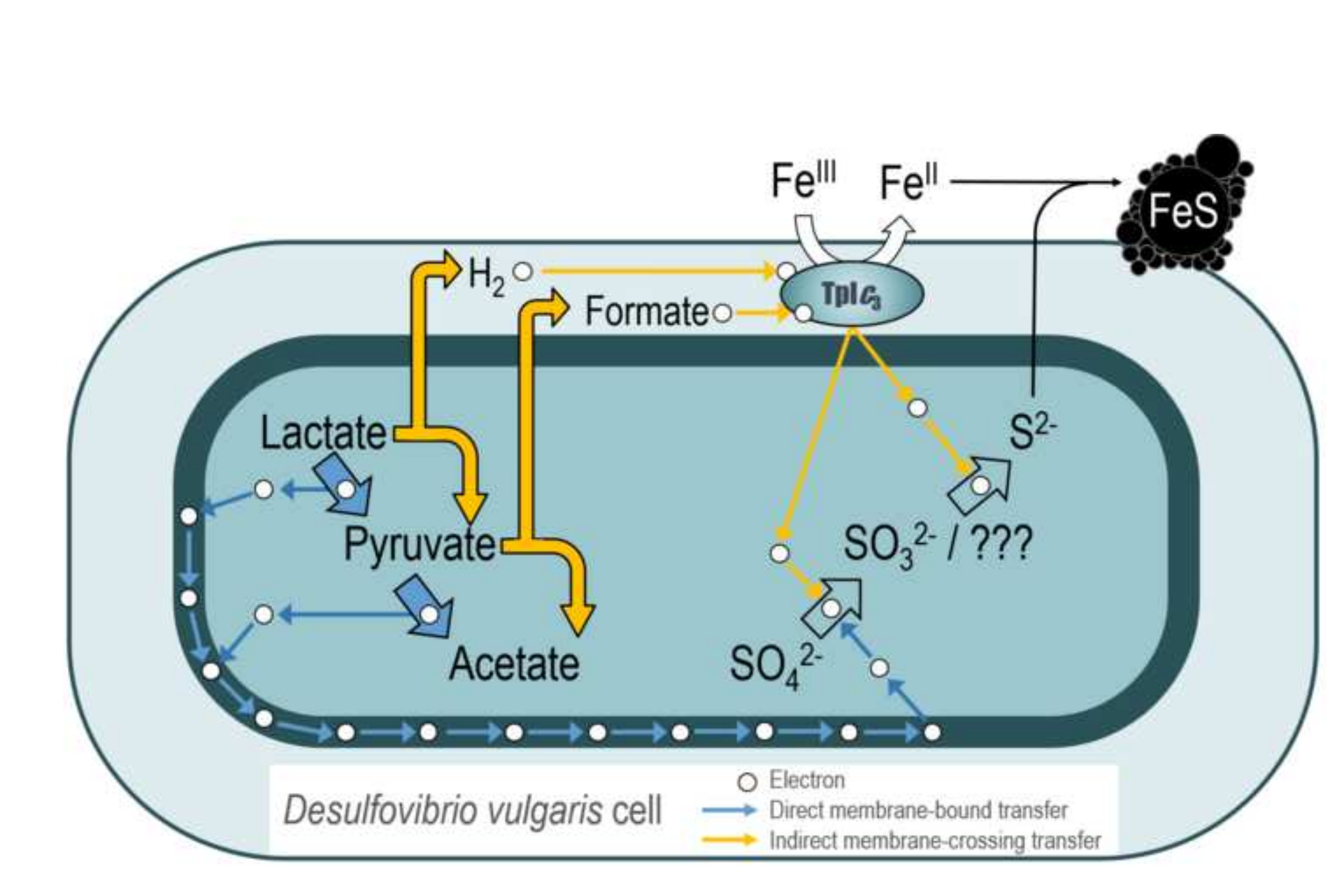

列

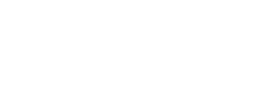
.
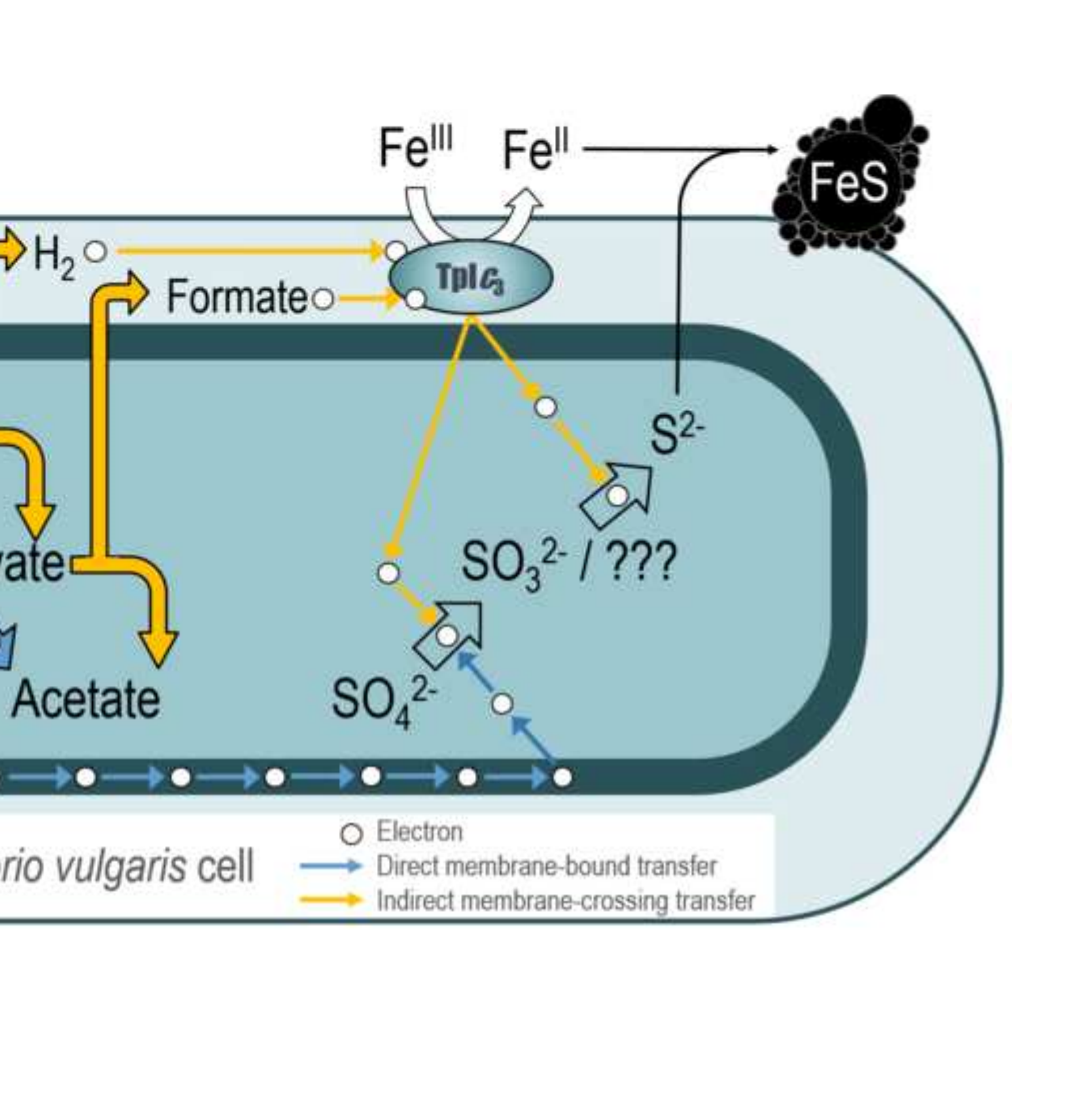

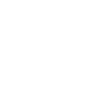

$+2$
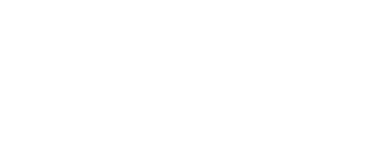

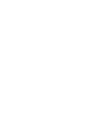

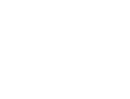

